NBER WORKING PAPER SERIES

\title{
THE ECONOMICS OF IMMENSE RISK, URGENT ACTION AND RADICAL CHANGE: TOWARDS NEW APPROACHES TO THE ECONOMICS OF CLIMATE CHANGE
}

\author{
Nicholas Stern \\ Joseph E. Stiglitz \\ Charlotte Taylor \\ Working Paper 28472 \\ http://www.nber.org/papers/w28472 \\ NATIONAL BUREAU OF ECONOMIC RESEARCH \\ 1050 Massachusetts Avenue \\ Cambridge, MA 0213 \\ February 2021, Revised February 2022
}

With thanks to Philippe Aghion, Tim Besley, Amar Bhattacharya, Robin Burgess, Geoff Heal, Cameron Hepburn, Haaris Mateen, Sanjay Reddy, James Rising, James Rydge, Andrew Steer and Bob Ward for valuable discussion. We are very grateful to the editors and referees who provided careful and insightful reviews of previous versions of this manuscript. Indeed, the editors played an important role in shaping the final version. This paper is a substantially revised version of "The Social Cost of Carbon, Risk, Distribution, Market Failures: An Alternative Approach". This version of the paper has been shaped by insightful reviews from the editors of the Journal of Economic Methodology and two anonymous referees, whose constructive feedback helped us to clarify and further hone our arguments. The main purpose of the revisions we have made to NBER working paper number 28472 is to emphasise more strongly our arguments relating to the appropriate methodology for economic analyses of climate change. The most important change is that the paper has been restructured to group our criticisms of Integrated Assessment models (IAMs) into three categories. Sections 3, 4 and 5 deal with these in turn: 3) problems that IAMs cannot address, and for which alternative approaches are necessary; 4) issues on which there has been some-in some cases, considerableprogress, but which require deeper treatment if the results of IAMs are to carry weight in policy discussion; 5) issues that the IAMs could address, but with extreme difficulty, and which have typically not been addressed, and on which many aspects of IAMs bias results. Further significant changes have been made to sections 1 and 7 of the paper, so as to emphasise our argument that addressing the full set of policy challenges presented by climate change will require a diversity of models and analytical approaches. The views expressed herein are those of the authors and do not necessarily reflect the views of the National Bureau of Economic Research.

NBER working papers are circulated for discussion and comment purposes. They have not been peer-reviewed or been subject to the review by the NBER Board of Directors that accompanies official NBER publications.

(C) 2021 by Nicholas Stern, Joseph E. Stiglitz, and Charlotte Taylor. All rights reserved. Short sections of text, not to exceed two paragraphs, may be quoted without explicit permission provided that full credit, including $\odot$ notice, is given to the source. 
The Economics of Immense Risk, Urgent Action and Radical Change: Towards New Approaches to the Economics of Climate Change

Nicholas Stern, Joseph E. Stiglitz, and Charlotte Taylor

NBER Working Paper No. 28472

February 2021

JEL No. H0,Q0

\begin{abstract}
Designing policy for climate change requires analyses which integrate the interrelationship between the economy and the environment. We argue that, despite their dominance in the economics literature and influence in public discussion and policymaking, the methodology employed by Integrated Assessment Models (IAMs) rests on flawed foundations, which become particularly relevant in relation to the realities of the immense risks and challenges of climate change, and the radical changes in our economies that a sound and effective response require. We identify a set of critical methodological problems with the IAMs which limit their usefulness and discuss the analytic foundations of an alternative approach that is more capable of providing insights into how best to manage the transition to net-zero emissions.

Nicholas Stern

Dept. of Economics

London School of Economics

Houghton St.

London WC2A 2AE

United Kingdom

n.stern@1se.ac.uk

Joseph E. Stiglitz

Kravis Hall, Room 543

Columbia University

665 West 130th St.

New York, NY 10027

and NBER

jes322@ columbia.edu

Charlotte Taylor

Grantham Research Institute

on Climate Change

London School of Economics

C.A.Taylor@1se.ac.uk
\end{abstract}




\begin{abstract}
Designing policy for climate change requires analyses which integrate the interrelationship between the economy and the environment. We argue that, despite their dominance in the economics literature and influence in public discussion and policymaking, the methodology employed by Integrated Assessment Models (IAMs) rests on flawed foundations, which become particularly relevant in relation to the realities of the immense risks and challenges of climate change, and the radical changes in our economies that a sound and effective response require. We identify a set of critical methodological problems with the IAMs which limit their usefulness and discuss the analytic foundations of an alternative approach that is more capable of providing insights into how best to manage the transition to net-zero emissions.
\end{abstract}

\title{
Keywords
}

climate change; extreme risk; market imperfections; climate policy; integrated assessment; social welfare; innovation

\section{Introduction: our basic methodological arguments}

Two critical questions confront the world today in response to the immense challenges of climate change. First, how aggressive should it be in combatting climate change-what should our targets be? Second, how best to achieve those targets-how will our economy have to change and what are the best instruments for inducing those changes? The international community has reached a broad consensus in answering both questions: In the Paris agreement of 2015 , there was a commitment (Article 2 ) to limit warming to "well below 2 degrees Celsius above pre-industrial levels and pursuing efforts to limit the temperature increase to 1.5 degrees Celsius...". An increasing number of countries have established a target of net carbon neutrality by 2050 , broadly consistent with that view ${ }^{1}$. There is a shared understanding that this will involve fundamental structural change in our economies, including in the major systems of energy, transport, cities, and land. And there is

\footnotetext{
${ }^{1}$ Since the Paris agreement, many countries and international institutions are now focussing on a target of 1.5 degrees Celsius, in part influenced by the IPCC report of 2018 on 1.5 degrees Celsius showing that it is much safer than 2 degrees Celsius (IPCC, 2018). That target of 1.5 degrees Celsius formed the basis of much of the discussion on goals and strategies at COP26 in Glasgow, November 2021. 90\% of emissions are now covered by countries with net zero targets (Climate Action Tracker, 2021).
} 
a broad consensus to use a wide variety of measures, including carbon pricing, programmes for green investments, programmes for system design or reform (e.g. of cities or power grids), interventions in capital markets, and standards and regulations, as reflected in the Stern-Stiglitz Commission's Report (2017), IEA (2021) and IMF (2021).

This consensus stands at odds with a major stream of thought within the economics profession. Much of the economics of climate change has centred on Integrated Assessment Models (IAMs). Using standard IAMs, with their choice of calibration, has led some prominent economists to conclude that "societal optimisation" entails accepting an increase in temperature of around 3.5 to 4 degrees Celsius (Nordhaus, 2018a), an increase seen as catastrophic by many, especially climate scientists:

"In the DICE model, it is essentially infeasible to attain the stringent temperature target of $1.5^{\circ} \mathrm{C}$, and the $2^{\circ} \mathrm{C}$ path requires negative emissions in the near term. Another finding, much more controversial, is that the cost-benefit optimum rises to over $3^{\circ} \mathrm{C}$ in $2100 "$, Nordhaus (2018a, p. 452).

Moreover, many economists, using such models, have argued that public interventions should focus on getting the price of carbon emissions correct, and, consistent with their target, argue for a price (reflecting the "social cost of carbon" -SCC) of around \$50 a ton of carbon by 2030 (in 2007\$ and assuming a 3\% discount rate ${ }^{2}$ ) (US Government, 2016), much lower than the numbers advocated even by those suggesting the use of a far wider range of instruments. In this perspective, policy analysts need not worry about how to foster and manage the multiple, large structural changes that might accompany the green transitionwith the right carbon price, the market will take care of it all.

Our central question in this paper is how do we explain the disparity between the conclusion of the international community and the standard IAMs about the appropriate targets and instruments? Between the standard economists' preference for price interventions and their widespread rejection in practice, as the only, or indeed primary,

\footnotetext{
${ }^{2}$ On discounting, and on major failings in its discussion in much of the literature on climate economics, see section 6 below.
} 
form of intervention? Who is right? The conclusion of our analysis is that it is not the international community which has gone astray but the IAMs. The paper explains why.

We argue that whilst the integration of economic and environmental analysis is necessary, the particular methodology employed by IAMs, notwithstanding their dominance in the economics literature, has serious shortcomings, which become particularly relevant in relation to the realities of the immense risks of climate change and of the radical changes in our economies that a sound and effective response requires. These shortcomings limit these models' ability to provide guidance either with respect to the appropriate climate goals or how they should best be obtained. We are concerned both with the underlying normative framework, essentially expected utility maximisation, and with basic problems in their descriptions of structural change, markets and technologies, and distributional questions. The former set of problems on the normative framework, aspects of which Pindyck (2013), Stern (2013), and Heal and Milner (2018) earlier had called attention to, are of a kind that cannot be corrected with further research, for instance by introducing more realistic damage functions. And altering the model to include a better description of structural and systemic change, dislocation and how markets actually function would involve a range of models very different from IAMs. Whilst there has been a valuable literature on improving some of the deficiencies of early IAM modelling, many of these shortcomings are a generic part of the approach.

Moreover, at the core of the standard IAM methodology is an analysis of intertemporal trade-offs; how much the current generation should sacrifice in order for future generations to be spared the devastation of climate change. Rising to the climate challenges does indeed involve deep normative questions, including how different generations' welfare is to be compared and the rights of future generations. But the world has been much more focused than the IAMs on a different set of issues, the risks of catastrophic consequences. These potentially catastrophic risks are in large measure assumed away in the IAMs.

Efforts to incorporate, even in a limited way, some of these issues and introduce more severe damage functions and different assumptions on technology or distribution generate markedly different conclusions about the optimum trajectories. But that produces another 
and very important problem with IAMs. Results over the past two decades have increasingly shown that the "optimal" trajectory and the SCC are extraordinarily sensitive ${ }^{3}$ to the precise specification of the model (Neelin et al., 2010; Budolfson et al., 2017; Gillingham et al., 2018). Some of the more plausible specifications of parameters and functional forms concerning damages, technologies and distribution can generate results more akin to those of the international consensus than to those of Nordhaus. But such sensitivity make the results of very limited usefulness.

We conclude therefore that the IAMs have very limited value in answering the two critical questions posed in our first sentence. They fail to provide much in the way of useful guidance, either for the intensity of action, or for the policies that deliver the desired outcomes.

In spite of these basic problems of methodology and sensitivity, the IAMs have had enormous influence, especially in the United States, and their shortcomings have had serious policy consequences. The IAMs have been particularly influential in the calculation of carbon prices for use in appraisal of public programmes. They have been used to suggest relatively low levels for carbon taxes. And they have been used to argue that policy on climate change should be overwhelmingly dominated by carbon pricing. They have played a major role in IPCC reports ${ }^{4}$ on policy, which, in turn, have played a prominent role in public discussion. They continue to play a very powerful role in the research activities of economists working on climate change. Given the severe limitations of the IAMs, and the multitude of key issues that arise in fostering a green transition, it makes sense to adopt a diversity of approaches to analysis and modelling to understand and illuminate these issues and relevant policy responses- a point we develop in the final section.

\footnotetext{
${ }^{3}$ Even though Nordhaus (2018a, p. 454-5) has recognised this sensitivity and lack of robustness, advocates of these types of models do not seem to have recognised sufficiently clearly that the implication is that there can be little confidence in the suggestion that optimum paths involve a 3.5 to 4 degrees Celsius temperature increase.

${ }^{4}$ There are three Working Groups (WG) in the IPCC, I physical sciences, II impacts and adaptation, III mitigation. It is WGII and WGIII that have consistently emphasised IAMs. WGI has emphasised risks strongly, developing ever increasing concerns over these risks - see in particular the $\mathrm{WCI}$ report from the $6^{\text {th }}$ Assessment Review, published in August 2021.
} 
Our first task in this paper is to argue that, as a methodological approach, the optimisation framework embodied in IAMs is inadequate to capture deep uncertainty and extreme risk, involving potential loss of lives and livelihoods on immense scale and fundamental transformation and destruction of our natural environment. The central problem facing the international community and national governments is how to respond to the deep uncertainty associated with climate change, where we know that we do not know how things may unfold, but we do know that there are scenarios, with not insignificant plausibility or probabilities, that have enormous consequences. That should be the focus; however, the focus of IAMs has been disproportionately on intertemporal trade-offs, on how to evaluate the environmental benefits at some time in the future versus the sacrifices we make today. This fundamental deep uncertainty has rightly moved to centre stage in public discussion, and the setting of global targets. At the same time, we recognise that risk and uncertainty and intertemporal values are interwoven in both analysis and decisions and we explore that explicitly towards the end of the paper, including arguing that the issues around discounting have received misleading treatment in much of the climate literature.

Practically, the world has taken an alternative methodological approach to simple maximisation of expected utility, which we refer to as the guardrail approach. This asks what needs to be done to avoid the most extreme damages, including what targets (e.g. reflected in acceptable temperature increases) to adopt, taking account of the costs of achieving those targets, and assessing whether they are even feasible. It is because the international community and most national governments have come to the conclusion that avoiding the potential extreme (but not fully known) consequences of going beyond 1.5 degrees (or "well below 2 degrees" as in the 2015 Paris Agreement) can almost surely be attained within an acceptable cost that there has been an agreement to proceed with those targets. ${ }^{5}$ Indeed, when the 2018 IPCC special report revealed that there was much greater

\footnotetext{
${ }^{5}$ As the quotation from Nordhaus above suggests, Nordhaus casts doubt on the feasibility of attaining the targets of 1.5 to 2 degrees Celsius. This is a conclusion presumably based not on an analysis of an optimisation model, but of the extreme sacrifice that would need to be borne. This speaks to a number of assumptions embedded in his model. Needless to say, other analysts, including the Stern-Stiglitz Commission (2017), have come to quite different conclusions.

The economic feasibility of achieving these targets at moderate costs is quite apart from the political economy issues about whether such targets can be achieved within current political frameworks. See the discussion below.
} 
risk at 2 degrees than at 1.5 degrees, the international community responded by revising downward substantially their temperature targets. It helped, of course, that at the same time advances in technology made it clear that more ambitious targets could be achieved at relatively little (or negative) costs. Indeed, COP26 in Glasgow in November 2021 worked largely with a 1.5 degrees target.

Nordhaus and others supporting the IAM approach are focused on the non-linearity in costs - if one attempts to reduce carbon emissions to achieve 2 degrees, the costs rise so high as to be, for all practical purposes, infeasible. As we note below, the international community is focused on the non-linearity in risks - if one doesn't reduce carbon emissions to achieve at least 2 degrees, the risks rise so high as to be intolerable. At the same time, the costs of limiting net emissions (including, if necessary, carbon capture and storage and carbon sequestration) are sufficiently limited that such trajectories are indeed feasible. The fact that there is such disagreement reinforces our emphasis on the importance of risk and uncertainty.

The major political opposition to this consensus comes from interests who might be adversely affected and who believe that they have not been adequately protected. This highlights the centrality of the distributive and political economy issues, to which we turn in section 4 of the paper. Some special interests, including some of those in the fossil fuel industry, have seized upon the IAMs to argue for a more muted response to climate change. ${ }^{6}$

Our second task is to show that, beyond the optimising framework, the internal workings of the IAM approach not only do not grapple with the challenge of major structural change, but also generally omit market failures, absences and malfunctioning, the management of which are key to effective policy making. We cannot assume that, except for the greenhouse gas externality, all markets work well, or that where they do not, the government has fully and effectively dealt with the failures. And similarly with issues around distribution and the

\footnotetext{
${ }^{6}$ For instance, using variants of such models, the Trump administration hugely diminished the SCC to \$8 in 2030 in 2018 dollars. It used these numbers to justify replacing the Obama era Clean Power Plan with Trump's Affordable Clean Energy rule, which allowed far more emissions from existing coal-burning energy plants.
} 
appropriate approach to discounting. In so doing we shall indicate that ignoring these issues often involves a bias towards weaker action and an excessively narrow approach to policy which insists on the overwhelming predominance of carbon prices. Carbon prices should indeed be centre stage but alongside a range of other policies.

We present our criticisms of IAMs under three categories,

A) The first set consists of the problems that IAMs cannot address, and for which alternative approaches, examined in this paper, are necessary. Of central importance are:

i) the assumption of deep uncertainty, where the outcomes (with associated probabilities) cannot be fully described;

ii) the failure to deal with extreme risk (different from deep uncertainty-fat-tailed distributions involving catastrophic outcomes, as Weitzman has emphasised (Weitzman, 2009)), where expected utilities may not be defined;

iii) the failure to take into account the endogeneity of preferences, where welfare functions of the standard kind, based on fixed utility functions, are not defined.

B) This set concerns those issues on which there has been some-in some cases, considerable-- progress, but which require deeper treatment if the results of IAMs are to carry weight in policy discussion. Key examples are:

i) intragenerational distribution, vested interests and political economy;

ii) damage functions, where impacts can be immense and there are large irreversibilities (the importance of which is limited in the absence of uncertainty), non-linearities, and complex feedback effects, giving rise to tipping points;

iii) the functional forms and parameters in cost functions.

C) The third category involves issues that the IAMs could address, but with extreme difficulty, and which have typically not been addressed, and on which many aspects of IAMs bias results. Many of these relate to a flawed description of the underlying economy; if the underlying descriptive model is flawed, normative analyses based on that model are an unreliable guide for interventions- but most importantly (see section 2), the problem is that the standard model implicitly makes the assumption that there are no limitations in government ability to redistribute incomes and correct market failures, and that the government in fact has done so. Central amongst these issues are: 
i) multiple and major market failures, beyond the greenhouse gas externality, which give rise to transition risks, entailing dislocation and adjustment costs - and the employment of a wider range of instruments to address climate change within a context of market failures; standard second best theory ${ }^{7}$ provides a strong warning about policies predicated on assuming only a single market failure (here, that of climate change);

ii) complex major systems --where a narrow focus on marginal analysis fails;

iii) technological change-an area in which markets are never optimal, deficiencies in "market solutions" are amplified by possibilities of increasing returns to scale in both action and discovery, and in which path dependency is crucial.

It would be very difficult to reformulate IAMs to tackle the issues raised in (C) and models reformulated with that intent would be methodologically very different from current IAMs. Indeed the issues are likely to require a range of perspectives and models, as we argue at the end of the paper. Our remarks about the difficulties that arise for the analysis of climate change, relating to extreme risk and the fostering of very rapid change, of course apply to other areas of economics where these issues are also of great importance. These include biodiversity and pandemics. Our remarks about the importance of a whole class of market imperfections in these kind of problems are also more general than just for climate change, and so too many of our comments about distributive effects. Thus, this paper makes no claim either to the originality of our criticisms nor to the comprehensiveness of our analysis ${ }^{8}$ - there are, for instance, further critiques of the IAMs. What is perhaps remarkable, though, is that economists working in that terrain seem not to have taken on board the insights of related subdisciplines, such as public economics and the decision sciences, and the critiques of analogous models in macroeconomics. In this paper, focusing on the economic analysis of climate change, we hope that by drawing attention to the depths of the limitations of the IAMs and suggesting alternatives we provide further impetus to the exploration and use of a wider range of approaches to modelling in economics as a whole.

\footnotetext{
${ }^{7}$ See section 5.1 .

${ }^{8}$ There are other important normative and technical issues, extensively discussed elsewhere. For instance, the assumptions of time separable utility functions and the malleability of capital are crucial for dynamics.
} 
The paper is organised as follows. In the next section we set out briefly the basic underlying structures of IAMs. Section 3 examines basic normative issues and the fundamental inadequacies of IAMs in relation to deep uncertainty, extreme risk, and, more broadly, the first set $(A)$ of the criticisms above. Section 4 looks briefly at modifications and extensions of early IAMs to address some of the problems around specific climate damages and costs of action and other issues in the second set, (B), of criticisms. Section 5 examines a set of issues which are critical to action and delivery of targets, but which are extremely difficult to build into IAMs in a way which could helpfully inform policy-- the third set, (C), of the criticisms. In section 6, we present the core arguments concerning discounting, including how they interweave with risk and uncertainty and the misleading treatments of discounting in much of the literature in the economics of climate change. We chart some ways forward for analyses that tackle the issues we have raised in section 7.

\section{The standard descriptive and analytical framework: problems and biases}

The methodological criticisms we raise in this paper are focused on the analysis of policy towards climate change on the basis of an aggregative growth model, with an infinitely-lived representative individual whose welfare is described by a sum or integral of expected utility, which links current emissions of greenhouse gases to current output; links cumulated emissions to temperature increases and climate change; and then climate change to economic damage, usually expressed in terms of a percentage loss of output. Typically, the only market failure in these models relates to carbon emissions; that is, but for the climate externality, the economy is fully efficient. Further, for the most part, technical change is taken to be exogenous. We refer to this as the "standard model" and it is the approach embodied in most IAMs, although there are by now many variants.

There are many important ways in which the standard intertemporal, representative agent model fails to provide a good description of our economy for the purpose of understanding behaviour and policy towards intertemporal allocations (Kirman, 1992). ${ }^{9}$ The problems are of particular importance for the study of policy towards climate change because of the

\footnotetext{
${ }^{9}$ To take but one example: that model predicts much higher savings rates than those actually observed (Carroll, 2000).
} 
centrality to climate policy of extreme risks, multiple market failures, processes of technical and systemic change, and intra and inter-temporal distribution. Thus, these models are methodologically ill-suited to serve as the modelling foundation for understanding policy on climate change. To quote the fourth of Dani Rodrik's "Ten Commandments for Economists": "unrealistic assumptions are ok; unrealistic critical assumptions (his italics) are not ok" (Rodrik, 2015, p. 213).

We begin, in sub-section 2.1, by setting out the "standard model". We introduce issues around distribution, risk, and technical change very briefly in sub-section 2.2 , and return to them in more detail in subsequent sections.

\subsection{The standard model}

The standard model describes society as if the infinitely-lived, representative agent maximised intertemporal utility,

(1) $W \equiv \int U(C, E) e^{-\delta t} d t$

where $\delta$ is the pure rate of time preference, measuring the extent to which utility in future years is weighed less than utility today, $\mathrm{C}$ is consumption and $\mathrm{E}$ is a measure of the quality of the environment. This maximisation by the individual agent, taking $E(t)$ as given, is subject to resource constraints, as in (2) where output is a function $\mathrm{F}(\mathrm{l})$ of $\mathrm{K}$, capital, and $\mathrm{E}$ :

(2) $Q=F(K, E)=C+I+e$

where I is investment and e is expenditure on carbon mitigation. In the most simplified version of the model, $\mathrm{E}$, the environment, is simply the level of atmospheric concentrations of greenhouse gases. The evolution of $\mathrm{E}$ and $\mathrm{K}$ are described by

(3) $d E / d t=\psi(F(K(t), E(t)), e)$, and

(4) $d K / d t=I-\mu K$ 
where $\mu$ is the rate of depreciation of capital. (3) implies that the increase in greenhouse gas concentrations is a function of output, E itself, and effort at emissions abatement, e.

Since the environment is a (global) public good, in the absence of carbon pricing or regulations, an individual would set e at 0 . This, together with the transversality condition ${ }^{10}$, defines the trajectory "business as usual."

By contrast, the optimal trajectory is that where $\mathrm{e}(\mathrm{t})$ is set to maximise social welfare, defined as the same maximand (1) as above. This is a crucial methodological assumption.

If it is to be achieved via individual choice then private and social objectives, incentives and understanding of the way the world functions must be aligned. In this model, key to accomplishing that is determining the appropriate price of carbon. The marginal social cost of carbon (SCC) describes how much we are willing to pay today to improve the environment by reducing emissions by a unit. The SCC, measured in today's dollars, is

(5) $\mathrm{SCC}=\frac{\partial W}{\partial E} / U^{\prime}\left(C_{0}\right)$

Setting the marginal cost of abatement (the cost of reducing carbon) equal to the (marginal) social cost of carbon, and making such calculations along the whole optional time trajectory allows us to calculate the "optimal" carbon (and capital accumulation) trajectory.

We question both the underlying assumptions concerning maximands and the reliance on prices to align social and private interests. We argue below that it is far more plausible that: (a) individuals maximise an objective that is distinctively different from that which society maximises, or which a policymaker contemplates in considering alternative policies; (b) the constraints facing an individual may be markedly different from those facing government, so

\footnotetext{
${ }^{10}$ In a finite horizon model that would be that, at the horizon, the shadow value of "stocks", K and E, is zero; or tends to zero in an infinite horizon model.
} 
that even if the unconstrained maximands were the same, the constrained maximands differ; and (c) aligning the two, in general, cannot simply be achieved through a simple price intervention.

\section{Infinitely-lived individuals}

It is obvious that individuals are not infinitely-lived. Advocates of the model have responded by saying each generation cares about the next, passing on to them inheritances, so that it is as if there were a single individual maximising utility over an infinite lifetime. This, sometimes referred to as the dynastic model, has been well-studied, both theoretically and empirically, and has been rejected as a satisfactory representation of the economy (Wilhelm, 1996; Hurd and Smith, 2002; Wolff and Gittleman, 2014).

Alternatively, it is hypothesised that government engages in optimal intertemporal (intergenerational) redistributions, so that again (1) becomes the relevant maximand. But changes in the economic environment which would, if the model were an accurate depiction of the economy, lead to changes in government behaviour, do not (See Stern and Stiglitz (2021) for a more extensive discussion of some of the evidence against the dynastic model and its implications).

In either case, there is a simple relationship (necessary for optimality) between the marginal utility of consumption (income) at time $t$ and $t+1$ given by the Euler equation (in discrete time)

(6) $U^{\prime}\left(C_{t}\right)=U^{\prime}\left(C_{t+1}\right)(1+r) /(1+\delta)$

where $r$ is the rate of interest faced by the optimising individual.

Not surprisingly, (6) has been subjected to extensive empirical testing (Ascari et al., 2021). This simple model performs badly as a description of the economy and hence policies based on this model have to be treated with scepticism. 
The overlapping generations model: an alternative framework

An alternative is an overlapping generations model, which has each generation maximising its own well-being. In the absence of government intervention, as before, e $=0$, and we can solve for the coevolution of the economy, described by a discrete-time version of (3) and (4). ${ }^{11}$

The overlapping generations model has one key implication that differs markedly from the dynastic model: there is no relationship such as (6) governing the marginal utilities of different generations. Only if government optimally redistributes income across generations according to some intertemporal social welfare function, such as

(7) $W^{*}=\Sigma U_{t} /(1+\delta)$,

subject to the standard intertemporal societal resource constraints, would an equation analogous to (6) be satisfied.

There is rightly considerable scepticism of this model of the "benevolent government", maximising an intertemporal social welfare function of the form (7). The large body of research, some of which was cited earlier, against the dynastic utility functions, implies that the economy does not behave as described by such a model. ${ }^{12}$

The absence of such optimal intergenerational redistribution in turn has marked implications for the calculation of the marginal social cost of carbon. If one believes that there are optimal intertemporal redistributions, one would (incorrectly) infer that the observed interest rate reflects the (social) marginal rate of substitution over time. But no such presumption exists if the current generation is not making adequate provision for the future.

\footnotetext{
${ }^{11}$ For more on the implications see Stern \& Stiglitz (2021).

12 Note that the analogous model in macroeconomics has similarly been much criticised as methodologically flawed. Many, if not most, of the criticisms levelled against that model (which have received widespread but far from universal acceptance) apply to IAMs (Stiglitz, 2011).
} 
Making such presumptions about future environmental benefits and risks (which is the whole objective of the IAM analyses) also entails assumptions about the substitutability of these with those of ordinary consumption goods. Only if there is perfect substitutability (thus constant relative prices) can one use the goods' discount rate to evaluate future environmental effects.

In sum, the standard intertemporal, representative agent model performs badly, in general, in helping us understand individual intertemporal decisions and allocations, but further it is particularly misleading in the context of climate change. ${ }^{13}$

\subsection{Risk, distribution, market failures, technology}

The discussion of the preceding subsection ignored risk and distribution. Discussions of limited risk have been a prominent element in some IAM work, with "utility" being replaced with "expected utility"; but the expected utility approach is inadequate when confronted with deep uncertainty (where probability distributions are not generally well-defined) and extreme (catastrophic) risk (where expected utilities may not be defined (Weitzman, 2012)), an argument taken forward in section 3. Within the IAM literature, there have been modest attempts at incorporating distributional issues-which necessarily take us beyond the representative agent model and leave unanswered the fundamental question of how markets achieve the alleged equilibrium outcomes ${ }^{14}$, either before or after government intervention. But even the limited results have strongly undermined Nordhaus' conclusions about desirable targets (see section 4). Fundamental intergenerational distributional issues and their interaction with risk and uncertainty are examined in section 6 . There is little

\footnotetext{
${ }^{13}$ There is a red herring that defenders of the IAM sometimes raise: if the government today is considering optimising environmental policy across generations, shouldn't it have already considered optimising intertemporal distribution? The reality of climate change has meant that the world can't avoid dealing with the issue, and the issue inherently involves an analysis of long-term intertemporal consequences. While in a "first best" world, one might argue that the government should simultaneously think about other forms of intertemporal redistribution, there is little evidence that it is fully doing so; and there is compelling evidence that it has not done so in the past, so that one cannot look to current market interest rates as reflecting, in any way, societies' marginal rate of substitution across generations (for further discussion see section 6).

${ }^{14}$ That is, in the representative agent model, the individual simply solves for the optimal trajectory; but with heterogeneous individuals in the absence of a full set of futures markets, there is no basis in a decentralised economy to ensure that the economy is on an equilibrium trajectory, i.e. a trajectory that would have emerged had there been a full set of markets.
} 
scope within IAMs for the multiple and crucial market failures of real relevance to climate policy. We examine these in section 5 . Some progress can and has been made in IAMs in relation to technology (see section 4), but the basic structure of IAMs implies that they are not very helpful vehicles for examining rapid, endogenous and systemic structural and technological change (see section 5).

Subsequent sections will show how these omissions significantly "bias" the results of the analyses, thereby limiting the usefulness of the models for the key questions (the setting of targets and how to achieve them) they were supposed to help answer.

\section{Problems which are inherently beyond the scope of the standard model and a proposal}

\section{for an alternative framework}

In this section we examine the basic flaws in the normative framework underlying IAMs related to the deep uncertainty and extreme risk potentially involved in unmanaged, or weakly managed, climate change. This motivates our argument for the alternative "guardrail" approach to climate policymaking, which we describe in section 3.3. Sections 3.4 and 3.5 identify two further deep and fundamental methodological problems with the IAM.

\subsection{The nature of uncertainty and risk from climate change}

An emissions pathway consistent with plans submitted for Paris UNFCCC COP21, 2015, implies that we are headed for temperature increases of 3 degrees Celsius or more within a century (UNEP, 2020). Such temperatures carry grave risks to humankind and the planet as a whole. We have not seen temperature levels 3 degrees Celsius or more above pre-industrial levels for around 3 million years, and at that time sea levels were 10 to 20 metres higher than now (Dumitru et al., 2019). It is quite possible that we could see temperature increases of 4 or 5 degrees Celsius 150 years or so from now, temperatures which the world has not seen for tens of millions of years. The uncertainty around the consequences of concentrations of greenhouse gases in the atmosphere for temperature implies that even if we aim for 3 to 4 degree Celsius temperature rise, there would be a risk of 6 degrees Celsius 
of warming. These kinds of temperatures could involve sea-level increases of scores of metres and inundation of many of the coastal cities of the world.

Those kinds of temperatures would radically change lives and livelihoods across the globe. Many parts of the world would become uninhabitable. One of the most densely populated regions in the world, the North China Plain, would likely experience deadly heatwaves later this century with "wet-bulb" temperature exceeding the threshold defining what people can tolerate while working outdoors (Kang and Eltahir, 2018). Similar heatwaves could also occur in other densely populated parts of the world, such as North India. Hundreds of millions, possibly billions, would have to move, likely resulting in severe and extended conflict.

A global cascade of multiple tipping points in the climate system (Lenton et al., 2008) would be an existential threat to civilisation (Lenton et al., 2019).

After Glasgow UNFCCC COP26, November 2021, partially in response to a growing understanding of the potential magnitude of these risks, plans for many countries for emissions reductions have been strengthened (Climate Watch, 2021). Even if these are delivered in full, the mean temperature anticipated around the end of this century would be over 2 degrees Celsius with serious risks of more than 3 degrees Celsius (UNEP, 2021). And we may well be already close to tipping points in relation to the Amazon rainforest, permafrost, and Antarctic ice sheets (Lenton et al., 2019).

The stakes we are playing for are immense.

\subsection{Deep uncertainty and extreme risk}

Every aspect of climate change-the drivers, the pace, the economic impacts, the response to interventions-is marked by considerable uncertainty. Changes in demographics, preferences, and technology-the underlying drivers of the economy-- are hard to predict; and even more difficult are changes in politics, which can have first-order effects on so many of the relevant variables. 
When we combine the uncertainties-about climate science, about the "right" economic model, about the parameters of the models, about the changes in those parameters over time, about the political processes which affect both the environment and economyclimate policymaking is a quintessential example of decision making under uncertainty, where the decisions themselves affect the magnitude of the uncertainties.

Following Knight, we distinguish between risk and uncertainty. In the former case, all the possible outcomes and their associated probabilities are known; in the latter case they are not. The uncertainties affect economic trajectories, and the impact of market failures; they have an even bigger impact on the normative analysis. Some of the key concerns, such as those posed by non-stationarity, affect both the descriptive and normative analysis. The standard IAMs pay only limited attention to risk and ignore uncertainty. While in some cases the former can, with some difficulty, be incorporated into the analysis, the latter cannot, as we explain below.

Within the utilitarian framework, the simplest representation, in the presence of risk, is to replace $U$ in each of the maximands described so far with its expected value. This is almost surely an inadequate approach (see sections 3.5 and 6), but it is the simplest, and most in line with conventional economics. Because of concavity, $\mathrm{EU}(\mathrm{C})<\mathrm{U}(\mathrm{E}(\bar{C}))$, where $\bar{C}$ is the expectation of $\mathrm{C}$, and given the scale of risk and reasonable estimates of the degree of risk aversion, the disparity would be large. Thus, as climate change proceeds, risk increases, and the gap between the putative welfare of the "central or average case", analysed in any model that does not fully embrace uncertainty and risk, and the expected utility of future generations along actual trajectories becomes increasingly large. And it is biased: the difference between expected utility on paths in which climate action has been curbed to say 1.5 degrees Celsius and 3 degrees Celsius are far larger than in a model ignoring risk. That implies, of course, a greater willingness to pay to reduce the (likely) magnitude of climate change. ${ }^{15}$

\footnotetext{
${ }^{15}$ Effects on the marginal social cost of carbon are sensitive to the particular parameterisation of the utility function, suggesting another reason why a framework for policy analysis centred around the marginal social cost of carbon may be of limited usefulness.
} 
This is especially so once we take into account some of the compounding economic risks associated with a non-orderly transition (e.g. the costs associated with systemic fragility), and incorporate damage functions reflecting risks to life, health and biodiversity, and the consequences of extreme events, leading to the risks of extreme losses.

We face extreme risks. In their presence, for time sufficiently far into the future, EU(C) may not be well defined. The standard criteria of choosing policies to maximise expected intertemporal utility may fail because, with some widely used utility functions, all trajectories within a wide class ${ }^{16}$ may yield the outcome of minus infinity. ${ }^{17}$ This is especially so if the distribution of some of the relevant variables is fat-tailed, as Weitzman (2009) has argued could well be the case. Then, the standard descriptive model introduced in section 2.1 breaks down: it cannot "explain" individual behaviour and the trajectory of the economy in the absence of government intervention; and it cannot provide guidance as to socially desirable interventions.

Weitzman (2009) set out what he called the "Dismal Theorem" which followed from his argument, namely that these models could imply that present generations would be prepared to pay an infinite amount to avoid future catastrophe. The reason for this was that the potential catastrophes were immensely or immeasurably severe and the probability of them occurring was far from negligible. Others have suggested (Nordhaus, 2009) that the problem does not arise if the increase in risk occurs slowly enough and the discount rate is high enough, but Weitzman maintained that unbounded expected utilities present a fundamental problem with the whole approach and are not dependent on a particular formulation. Moreover, he argued that no plausible amount of discounting would remove the problem. ${ }^{18}$ As he put it (2012)-consistent with the thesis of this paper:

\footnotetext{
${ }^{16}$ Including possibly the central trajectory labelled as "optimal" by the IAMs.

${ }^{17}$ Our late friend Marty Weitzman was concerned with these issues and discussed them with us over the years.

${ }^{18}$ The point is that the further out in the future, the greater the uncertainty. But sufficiently severe adverse outcomes can occur with sufficiently high probability within finite dates such that the integral of expected utility over time is not defined (especially so if we take on board the ethical concerns raised in section 3.5). The interaction between discounting and extreme risk is examined in section 6 below.
} 
“.... I suspect rather strongly ...that the primary reason for keeping GHG levels down may be mainly to insure against high-temperature catastrophic climate damages."

There may still be some trajectories, achievable at moderate costs, whose outcomes are bounded. Societal welfare is best enhanced by taking actions which avoid the extreme outcomes occurring (with a significant probability). This is the perspective taken for the UN Paris climate agreement of 2015. If there are actions that strongly limit the probability that disastrous outcomes occur, and these entail modest costs, they should be undertaken. The relevant choice is only among those trajectories that avoid, or radically reduce the probability of, the disastrous outcomes (see Stern \& Stiglitz, 2021, for more on ranking alternative trajectories when all are unbounded). In the language of dynamic programming, we try, as best we can, to avoid the state valuation falling off a cliff. This is the guardrail approach. Its role in public discussion and international agreements is described in the next section.

\section{Deep uncertainty}

Deep uncertainty-where individuals do not know all of the possible outcomes and the probabilities of occurrence of different possible events ${ }^{19}$, and know that they don't knowpresents even more fundamental methodological difficulties for the IAM. In particular, it gives rise to incomplete orderings. This is inconsistent with the underlying (but rarely stated) hypothesis in the IAMs that there is a complete ordering. And, it is not just the incompleteness per se of the ordering that is the problem; it is where the incompleteness arises, which is the inability to describe and evaluate some of the most important, catastrophic outcomes.

While Savage subjective expected utility is used in many subfields in economics, especially where there are repeated events in which there can be some congruence between subjective probabilities and objectively observed frequencies, in a world that is everchanging, in a world of "unchartered territory," with deep uncertainty, such as climate

\footnotetext{
${ }^{19}$ Even the meaning of probabilities is questionable, as the long standing philosophical discussion leading up to Savage's work (discussed briefly below) makes clear.
} 
change, that framework and the axioms underlying it are not convincing. ${ }^{20}$ Savage himself suggested his framework was more appropriate for "small world" decisions-and if there were ever a set of problems that were not small world, those surrounding climate change would be among them. There is far from consensus on the axioms underlying expectedutility.

Kreps (1979) has argued that in the presence of extreme uncertainties, individuals do not act as if they maximise expected utility but show a preference for flexibility. This approach may be consistent with more precautionary behaviour, i.e. taking stronger actions to avert climate change than one would expect to see were individuals maximising their expected utility with levels of risk aversion normally observed. Others (e.g. Maskin, 1979) have argued that in the presence of "extreme ignorance" it is plausible that individuals (and societies) act in ways which show extremes of risk aversion, more akin to the max-min objective function than the maximisation of subjective expected utility. ${ }^{21}$ Gilboa and Schmeidler (1989) have provided a framework that allows for the integration of expected utilities in domains where there is not deep uncertainty and something more akin to the max-min principle in domains where there is. ${ }^{22}$

(We should emphasize there are still other fundamental critiques of the IAM's normative approach, maximizing discounted expected utility: For instance, the standard approach does not adequately differentiate attitudes towards risk from intertemporal preferences. See the discussion of section 6.)

In short, in the presence of deep uncertainty, the framework of maximising expected utility lacks credible foundations, and under plausible assumptions, rational individuals undertake more precautionary behaviour than might be suggested by such a model. ${ }^{23}$

\footnotetext{
${ }^{20}$ We have already noted that expected utility may not be well-defined, especially with fat-tailed distributions. ${ }^{21} \mathrm{He}$ also shows that this perspective carries over to social choices (in contrast to Harsanyi, who argues for a utilitarian social welfare function).

${ }^{22}$ The particular axiom that has been questioned is the "sure thing" principle. For a more extensive discussion see Heal and Millner (2018). Gilboa and Schmeidler's axioms give rise to what is referred to as ambiguity aversion.

${ }^{23}$ We are careful to say "might," because (a) we are not sure even how to proceed with using the expected utility framework in the circumstances delineated; and (b) we know that under plausible conditions, even were
} 


\section{Non-stationary analyses}

A central problem is that climate change is moving us into unchartered territory: we do not know how an increase in greenhouse gas concentrations will affect weather and how changes in climate will affect the economy, simply because our economy has never experienced in the lifetime of homo sapiens anything like what we are likely to face. We can extrapolate the future based on the past, but whether in these circumstances that makes sense is highly problematic. The underlying dynamics are not well-described by stationary processes (Milly et al., 2008). It is analogous to the problems of prediction in the years preceding the global financial crisis, when financial markets created new products which they claimed fundamentally changed the way the economy behaved; but the only data to forecast how the economy would behave was from an economy without these financial products. As it turned out, the extrapolations (forecasts) based on that data were wildly off the mark. In this case the problems are likely on a far bigger scale.

These concerns are especially important because of the large non-linearities associated with climate processes, which makes simple extrapolations from the limited climate change experienced thus far highly dubious.

The absence of a scientific basis to estimate probabilities of outcomes associated, say with climate change of 3.5 degrees Celsius, well beyond anything experienced, combined with the sensitivity of IAM analyses to those probabilities, in turn has profound implications for the policy relevance of IAMs: they provide no guidance on how to resolve differences in key judgements around risk and uncertainty, because they simply assume such differences away. ${ }^{24}$

\footnotetext{
we able to meaningfully assign subjective probabilities to different states, expected utility may not be well defined.

${ }^{24}$ It also provides a further critique of the representative agent model, which assumes that all individuals have common knowledge, sharing the same beliefs-obviously contradicted by the heated climate change debates. The IAMs to date have provided not even a suggestion of how societal welfare is to be maximised in a context in which there are disparate beliefs.
} 


\subsection{The guardrail approach}

We argued above that deep uncertainty has profound implications for how individuals actually behave and what are reasonable frameworks for individual decision-making. Here, however, we are concerned about societal, not individual, decision-making. Once we move into a world where there is neither consensus about utility functions (the welfare maximand) or probabilities or the functions describing damages or costs of abatement, the question arises: how can we reach societal agreement about what to do? How we aggregate disparate preferences and beliefs has been a longstanding question in economics and political science (see Arrow, 1951). ${ }^{25}$ In the case of climate change, we can observe how the global agreement, or consensus, as embodied in the Paris 2015 UNFCCC agreement, was reached: it became broadly accepted that with temperature increases over 2 degrees Celsius there was a significant probability of extremely bad outcomes, potentially so bad that there was a consensus that we should act strongly to try to avoid them. One did not have to have full agreement on the utility function, the damage or abatement cost functions, discounting, or the probabilities. All one needed was convincing evidence of sufficiently high probability of very adverse or catastrophic outcomes that could be avoided at moderate costs, and on that there was consensus across more than 190 countries.

From a formal point of view, it may not be possible to provide concrete social orderings across paths with potentially catastrophic outcomes. Attempts to use standard, sound utility functions can lead to divergent sums or integrals of social utility across a whole range of potential paths. We have, at best, partial rather than complete orderings. In this case the response, which makes sense, has been to follow a lexicographic approach, where we first rule out paths that involve unacceptable risks of catastrophe and then make our evaluations across paths which do not carry such risks ${ }^{26}$. That is the guardrail approach and has been expressed in this context in terms of an upper limit on acceptable temperature increases.

\footnotetext{
25 There is also no consensus among economists about how to make welfare judgments in a world where ex ante some individuals' probability judgments are clearly off the mark, e.g. where beliefs about climate change or future interest rates are untethered to reality; or in a world where those beliefs are changing and/or endogenous.

${ }^{26}$ The issue of divergent integrals and incomplete orderings in the context of extreme risk raises important research challenges on which we comment briefly in the final section.
} 
Having agreed on a reasonable, consensus goal, the task then is to find the best way of achieving that goal. The difference is analogous to that between cost-benefit and costeffectiveness analysis. In many arenas of policy where the benefits are hard to evaluatewars, regulations which affect health, safety and life itself or biodiversity-there is often resort to cost-effectiveness analysis. An agreement is first reached on goals and constraints, and economic analysis centres on the best way to achieve the given goals within the constraints.

Moreover, in the context of climate change, the focus is on avoiding the calamitous events, not average outcomes. IAMs, by contrast, focus on average outcomes in the sense of expected utility. The non-linearities identified in earlier IPCC reports (IPCC, 2014, 2018) imply significant reductions in those extreme risks if temperature rises can be kept well below 2 degrees Celsius, with the associated limitations in greenhouse gas concentrations. Recognising that stabilising temperature requires stabilising concentrations, the international community has focused on achieving net carbon neutrality by around $2150 .{ }^{27}$

This target setting or "guardrail" approach to policymaking has parallels in other arenas where we have rules which are designed to manage extreme risk. For instance, driving is not permitted if alcohol blood concentration is above a threshold. With cliffs or railway platforms there are restrictions on proximity to the edge. There are safety limits on the amount of certain substances in food or drink.

As a first approximation, there is an easily implementable modification to the approaches of the IAMs that can embed the guardrail approach. Assume, for a moment, that we were to buy into the representative agent model and all the other assumptions underlying the IAM. Associated with the agreed upon maximum temperature change there is a maximum level of atmospheric greenhouse concentration. Then we simply add a constraint to the intertemporal maximisation problem, that there never be greenhouse gas concentrations in excess of that level. Of course, this is only a first approximation-it misses out on risk and the other key ingredients emphasised earlier. And it would still embody many of the

\footnotetext{
${ }^{27}$ This simplifies the physics somewhat but embodies the basic scientific logic. Note that the path to net zero is important -atmospheric carbon concentration, the integral of net emissions over time, is what matters.
} 
problems analysed in section 5 below. Such an approach cannot, of course, help us answer the question of what our target should be; it simply helps us to understand the best "glidepath".

\subsection{Endogenous preferences}

Another key determinant of the evolution of the economy is the evolution of preferences. Standard welfare economics (and IAMs) is based on the presumption that preferences are fixed and unalterable; but they are not. They have been changing and, there is at least a degree of endogeneity in all the key parameters of the economy-demographics, technology, market structure, even preferences, are affected by policy, and policy itself is affected by the economic circumstances confronting a polity and citizens' beliefs.

The endogeneity of preferences has important implications for normative analysis. There are two reasons to believe that changing and endogenous preferences might lead to stronger climate policy being desirable than suggested by the IAMs. First, at least some weight needs to be given to those who care intrinsically about the environment and its preservation, and the evidence is that it is an increasing fraction of the population.

Forecasting these trends and reflecting Ramsey's dictum of no discrimination against future generations (see section 6 below) suggests, in fact, heavy weights should be placed on protecting the environment. Moreover, the costs of mitigation by behavioural adaptation may be low: is there any loss in well-being, appropriately assessed, if individuals adapt their diet, coming actually to prefer diets with less or zero meat? If not, it implies that one can achieve substantial reductions in carbon emissions with essentially no loss in "well-being."

We note that whilst endogeneity of preferences is very problematic for approaches using expected utility, it is not necessarily disruptive to a guardrail approach.

\subsection{Intergenerational equity}

As we have noted, the standard IAMs maximise discounted utility over time-equivalent to discounting the utility of future generations relative to those alive today (pure-time discounting). There has been substantial discussion in the literature on pure-time 
discounting, with Ramsey, Keynes and other philosophers arguing it is ethically

unacceptable. ${ }^{28}$

That is a view with which we would broadly agree. Attaching a lower weight to a future life, which is otherwise identical, simply because it occurs later, is essentially discrimination by date of birth. It is very difficult to find a justification for this in moral philosophy. For a more extended discussion, see Stern (2015) and Stern (2014a, 2014b), and briefly in section 6 below.

However, when such discounting is eliminated, for a wide range of apparently plausible utility functions and paths of development, the maximand (1) becomes undefined (or infinite), again providing no policy guidance. Again, this is an intrinsic problem with the methodology-not one which can be repaired by further research. ${ }^{29}$

\section{Multiple modifications of IAMs: some progress but serious problems of robustness}

A major and pioneering contribution to the economic modelling of climate change was William Nordhaus' important and admirable 1991 Economic Journal paper 'To slow or not to slow?'. Taking an emerging problem and applying the standard tools of economics was a sensible early contribution to the economics of climate change. Nordhaus' original DICE model launched a major literature on integrated assessment models (IAMs), and their scope has been expanded over the intervening years. In retrospect we can see that, over time, it has become more and more clear the potential risks were far bigger than recognised in 1991 and each of the six IPCC assessment reviews has looked more worrying than the last. The immensity of the risks, as we have argued, takes us outside the narrow confines of these models, yet the economics profession on the whole has been too slow to look beyond them.

\footnotetext{
${ }^{28}$ Rawls (1971) can be read as supporting this perspective. It has particularly strong implications with utility functions in which the environment explicitly enters into utility functions and is imperfectly substitutable with conventional consumption goods.

${ }^{29}$ An effect which looks like pure-time discounting comes from the argument that if there is some exogenous probability of extinction, then we adjust future utilities for the predictability of survival (see Chichilnisky et al., 2020 for analysis and references). But in the case at hand, those probabilities themselves are endogenous, a result of climate policy. It is perhaps worth noting that there are other methodologies that can, in some limited circumstances, be used to rank alternative trajectories, such as von Weizsacker's overtaking criterion, but invoking those would take us well beyond any IAM.
} 
In this section we will describe a set of criticisms (set (B) outlined in section 1) of the early IAMs, on which economists have made some progress. We highlight relevant contributions in the literature. These improvements to the IAMs, whilst worthy in their intent to tackle problems in early work, have demonstrated the models to be thoroughly unrobust, so unrobust as to be unhelpful to policymakers. Still, it should be noted that more reasonable implementations of IAMs, e.g. with more relevant damage functions, yield results for optimal trajectories and SCC that are far more in accord with the international consensus. Still, we reiterate the central message of the last section: those targets were set not on the basis of a refined intertemporal analysis, of the kind that is at the centre of IAM modelling, but on an analysis of risk ${ }^{30}$.

\subsection{Damage functions}

The damages from a global temperature increase are reflected, in most IAMs, by a proportionate reduction in overall output. For example, in Nordhaus' DICE models, losses from a 3 degree Celsius temperature increase are around 2.1 percent of GDP, and for a 6 degree Celsius temperature increase, 8.5 percent of GDP (Nordhaus, 2018b). There is no damage to capital stocks in most IAMs, nor any reduction in the underlying growth rate, which is assumed to be exogenously determined.

As we have already noted, a 4 degree Celsius, let alone a 6 degree Celsius, increase in temperature would have large and highly uncertain consequences, likely involving a massive disruption in livelihoods and severe loss of life across the world. What we know about climate change strongly suggests that damages increase non-linearly with temperature. Given that many parts of the world would have to be abandoned as submerged, or vulnerable to severe weather events, including outdoor temperatures intolerable to human beings, for extended periods (wet-bulb temperatures above 35 degree Celsius) (Xu et al., 2020), the assumption of no reduction in, or damage to, capital stocks is clearly untenable.

\footnotetext{
${ }^{30}$ In the Stern Review (Stern, 2007) for one of the chapters (chapter 6) we used the PAGE model developed by Chris Hope, which built in parameter uncertainty, although it did not incorporate the extreme risks we now see as of crucial importance. At that time, only the third IPCC assessment review was available.
} 
So too is the idea that there could be an unchanged underlying growth process. The estimates of damages from climate change calculated in those IAMs incorporating such damage functions are much smaller than that which is likely to occur.

Obviously, since damages are particularly intense in the upper tails of temperature distributions, small changes in mean temperature can have large effects on the probabilities of those extreme events; and given the complexity of the climate system and the fact, repeatedly emphasised, we are moving into unchartered territory, we can have only limited confidence in estimates of damage functions based on past data. ${ }^{31}$

There has been progress in the IAM literature in incorporating more realistic damage functions. Carleton and Hsiang (2016), Ciscar et al. (2019) and others provide thoughtful calibrations of damage functions. Hsiang et al. (2017) have produced an empiricallyestimated damage functions for the US. Climate and social tipping points have been incorporated into IAMs (see e.g. Cai et al 2016; Grubler et al. 2018; Yumashev et al. 2019; Dietz et al., 2021).

Not surprisingly, results on optimal policy change dramatically if the assumed damages from climate change are much larger. For instance, Moyer et al. (2014) show that when the assumption of exogenous growth is relaxed in DICE, SCC estimates can increase by orders of magnitude. Dietz \& Stern (2015) have also shown how a stronger damage function in DICE suggests a carbon price (in a setting of globally coordinated policy) of $\$ 32-103 / \mathrm{tCO}_{2}(2012$ prices) in 2015 , rising, in real terms, to $\$ 82-260 / \mathrm{tCO}_{2}$ within two decades, keeping the expected increase in global mean temperature to 1.5-2 degrees Celsius above pre-industrial levels. Similarly, Moore \& Diaz (2015) show that an alternative formulation of the damage function in DICE, which allows temperature effects on GDP growth, produces optimal policy consisting of much more stringent near-term mitigation, stabilising global temperature rise below 2 degrees Celsius. More recently, Hänsel et al. (2020) have shown that adjusting the

\footnotetext{
${ }^{31}$ This paper focuses on the methodological foundations of IAMs and alternative approaches, and is not intended to provide a comprehensive survey of the vast IAM literature. We emphasise, however, that the IAM literature itself has established the lack of robustness.
} 
parameters of DICE to reflect stronger economic damage functions, along with some of the latest climate science and a broad range of "expert recommendations" on the pure rate of time preference and the elasticity of marginal utility, as elicited by Drupp et al. (2018), brings the economically optimal climate policy path in line with the goals of the Paris Agreement. As we explain below, while they might make the IAMs seem more reasonable, these studies simply illustrate, but do not resolve, the extreme sensitivity of results in these models, which make them very weak frameworks for policymaking. And the problems of foundational weaknesses associated with extreme risk, deep uncertainty and the challenges of structural change are still not resolved.

\subsection{Intragenerational distribution}

Most IAMs deal with aggregate consumption as the argument of a social utility function, sometimes using broad regional sub-aggregates. This approach misses crucial distributional issues as it is the poorest who are hit hardest by the effects of climate change; see, for example, the cyclone in Mumbai and Hurricane Katrina in New Orleans both in 2005. And it is the poorest people who are least insured, who have the least resources to adapt and who usually live in areas that are least protected. The hardship that they bear would, for the value judgements of many, require strong weighting in valuations of damage and this is largely missed by the aggregate approach in IAMs. Nor can it be assumed that government can or will simply introduce actions and policies to "undo" these distributional effects.

Schumacher (2018) has demonstrated how equity weighting can lead to significantly higher global damages from climate change than those reported by unmodified IAMs. Using a modified version of RICE (Regional Integrated model of Climate and the Economy), called NICE (Nested Inequalities Climate-Economy model), Dennig et al. (2015) have shown that accounting for the distribution of consumption and damage within regions may be as important for climate change policy as the choice of discount rate. NICE has also been used to investigate the comparative importance of pure-time preference; inequality aversion; inequalities in the distribution of both damage and mitigation costs between rich and poor; and a damage function that does or does not assume catastrophic impacts at high global mean temperature increases. Highlighting the lack of robustness of IAM results, Budolfson 
et al. (2017) show that sub-regional inequalities have a larger effect on optimal policy than does adding catastrophic damages with certainty, at 4 or 6 degrees Celsius above preindustrial temperatures.

The cited literature does not, for the most part, incorporate simultaneously risk and distribution - taking into account, as we have noted, that those at the bottom face the most risk and are least able to bear it. Almost surely, then, optimal policies taking into account simultaneously risk and distribution would lead to even stronger climate policies. ${ }^{32}$

\subsection{Modified IAMs are unrobust}

We have described how various modifications have been introduced into IAMs, and their limitations. It is apparent that even mild modifications in the direction of greater realism in the assumptions and parameters put into the IAMs-more realistic damage functions or better taking into account distributive effects-- yield markedly different results. A similar sensitivity applies to functions describing costs of action for mitigation (Grubb et al., 2021).

While we have emphasised the multiplicity of instruments required to achieve an efficient and just green transition, IAMs have centred attention on the SCC. The problem is again that small changes in assumptions can yield large changes in the estimated SCC. A meta-analysis by Wang et al. (2019) found that studies using IAMs to estimate the SCC have produced values ranging from $-13.36 \$ / \mathrm{tCO}_{2}$ to $2386.91 \$ / \mathrm{tCO}_{2}$. From the perspective of a policymaker, this degree of unrobustness in the IAMs makes them unhelpful for guiding policy decisions.

Further, the problem of lack of robustness cannot be solved by conducting a meta-analysis and producing a central value. For instance, many SCC estimates in the literature do not take into account extreme values, do not reflect the latest climate science, and do not incorporate distributive effects; if 'good' and 'bad' studies are not appropriately weighted, a meta-analysis will not produce a result relevant for policy analysis, which clearly should take into account risk, distributive effects, and market failures.

\footnotetext{
${ }^{32}$ As we noted earlier, we should not assume (as the IAM model does) that the same forms and specifications of a utility function are relevant for both distribution and risk. To our knowledge, none of the work extending the IAM models to risk have addressed this issue.
} 


\section{Some central issues for policy which are difficult to incorporate into IAMs}

In this section we will examine a set of issues which are critical to climate policy but which are very difficult to build into IAMs (the third set of issues outlined in the introduction) in a way that could helpfully inform policy; indeed, as we suggest in the introduction, addressing them adequately requires sufficient changes in the model-and would generate sufficient changes in results-that it is questionable whether the resulting formulation should really be labelled as the same model.

\subsection{Making policy when key markets are absent or imperfect and governments have limited ability to correct market failures and to redistribute}

Changing the structure of an economy in response to climate change will involve a host of private-sector decisions, including those concerning investment and innovation, in the context of markets that are far from perfect. Government policy will shape those decisions. If emissions of GHGs were the only market failure, then basic Pigouvian theory says that optimality could be achieved with a tax equal to the marginal damage associated with the externality (Sandmo, 1975). ${ }^{33}$

But the world is not like that. There are multiple crucial market failures beyond that of the GHG externality which are highly relevant, including: (i) the absence of a full set of risk and futures markets; (ii) imperfections in information (including around $R$ and $D$, new products, carbon content of products, likely effects of climate change, e.g. on assets); (iii) imperfections in capital markets, related in part to the absence of a full set of markets and imperfections of information ${ }^{34}$; (iv) a pervasive set of other externalities, including those associated with networks (including grid structures, public transport, broadband, recycling), and with the co-benefits of limiting carbon emissions (including air, water and soil pollution); and ( $v$ ) market failures associated with non-convexities (increasing returns, learning effects, bankruptcy, etc).

\footnotetext{
${ }^{33}$ As we see in the following this conclusion no longer holds in the context of other market failures.

${ }^{34}$ Advances in the economic understanding of the consequences of imperfect information have explained why this is inherent (Stiglitz, 2002).
} 
The standard methodological approaches in the economics of climate change have, in large measure, ignored these further market failures, as they focused on the GHG externality. That externality is indeed at the heart of the story, but a methodology that does not take into account the multiple other market failures gives a grossly distorted view of appropriate climate policy. These additional failures are not marginal issues or footnotes; they should be at the heart of policy.

The fact that standard IAMs do not incorporate market failures other than the GHG externality limits their usefulness for policy. One of the most important insights in economics in the middle of the last century was the theory of the second best and more broadly modern public economics ${ }^{35}$. It observed that the consequences of removing a market failure in the context of a world where that market failure was the only market failure were markedly different from the consequences of removing a market failure in the context of a world in which there are multiple market failures (Lancaster and Lipsey, 1956; Meade, 1952). Much of the work in IAMs seems to have forgotten that lesson, or (implicitly) assumed that somehow government has remedied all market failures other than that associated with climate change.

Some key relevant market failures are set out in the Table 1, organised in a way that hints directly to relevant policy options. These failures are quantitatively significant. For instance, around $15 \%$ of world deaths in 2018 were linked to air pollution, much of it associated with the burning of fossil fuels (Vohra et al., 2021). Action to eliminate the burning of fossil fuels can strongly reduce deaths and damage to health from air and other pollution.

We have described in Table 1, in the last column, policy measures which could tackle, not fully but substantially, the market failure defined in the row. For example, labelling and information requirements on cars, domestic appliances, and other products lead to more informed consumers. Regulation on disclosure of information on carbon content of goods or

\footnotetext{
${ }^{35}$ As embodied in the Journal of Public Economics which we helped found in 1972, with the leadership of Tony Atkinson.
} 
in financial portfolios can have strong effects ${ }^{36}$. These examples illustrate a more general proposition: in the presence of market failures, significant reductions in carbon emissions may be achievable at much lower societal cost than would be the case in the "perfect markets" model.

Table 1: Six market imperfections relevant for tackling climate change ${ }^{37}$

\begin{tabular}{|c|c|c|}
\hline Market Failure & Description & Policy Options \\
\hline Greenhouse gasses (GHGs) & $\begin{array}{l}\text { Negative externality } \\
\text { because of the damage that } \\
\text { emissions inflict on others. }\end{array}$ & $\begin{array}{l}\text { Carbon tax/ cap-and-trade/ } \\
\text { regulation of GHG emissions } \\
\text { (standards), public } \\
\text { investments. }\end{array}$ \\
\hline $\begin{array}{l}\text { Research, development and } \\
\text { deployment (R,D \& D) }\end{array}$ & $\begin{array}{l}\text { Firms do not fully } \\
\text { appropriate the benefits of } \\
\text { their R \& D; knowledge } \\
\text { spillovers }\end{array}$ & $\begin{array}{l}\text { Tax incentives, support for } \\
\text { demonstration/deployment, } \\
\text { publicly funded research. }\end{array}$ \\
\hline $\begin{array}{l}\text { Imperfection in risk/capital } \\
\text { markets }\end{array}$ & $\begin{array}{l}\text { lack of access to capital (e.g. } \\
\text { even for privately profitable } \\
\text { climate mitigation } \\
\text { investments); inability to } \\
\text { divest of risk in investments } \\
\text { in new technologies }\end{array}$ & $\begin{array}{l}\text { Government green lending } \\
\text { (green development banks); } \\
\text { risk sharing/reduction } \\
\text { through guarantees; } \\
\text { convening power for co- } \\
\text { financing. }\end{array}$ \\
\hline $\begin{array}{l}\text { Networks and system } \\
\text { change }\end{array}$ & $\begin{array}{l}\text { Coordination of multiple } \\
\text { supporting networks and } \\
\text { systems, often marked by } \\
\text { large non-convexities. } \\
\text { Marginal analysis, the } \\
\text { cornerstone of classical } \\
\text { economics, fails }\end{array}$ & $\begin{array}{l}\text { Public investment in } \\
\text { infrastructure to support } \\
\text { integration of new } \\
\text { technologies in electricity } \\
\text { grids, public transport, } \\
\text { broadband, recycling. } \\
\text { Planning of cities. }\end{array}$ \\
\hline
\end{tabular}

\footnotetext{
${ }^{36}$ Labelling has been shown to influence purchasing decisions (European Commission, 2019).

${ }^{37}$ Note that the policy options in the third column are not exhaustive.
} 


\begin{tabular}{|l|l|l|}
\hline Information & $\begin{array}{l}\text { Lack of awareness of } \\
\text { technologies, carbon } \\
\text { content of portfolios or } \\
\text { products, climate risks. }\end{array}$ & $\begin{array}{l}\text { Labelling and information } \\
\text { requirements on cars, } \\
\text { domestic appliances, } \\
\text { products more generally; } \\
\text { disclosure requirements, } \\
\text { especially on financial } \\
\text { institutions; stress tests; } \\
\text { increased awareness of } \\
\text { options. }\end{array}$ \\
& Benefits beyond market & $\begin{array}{l}\text { Policies valuing ecosystems } \\
\text { and biodiversity, recognising } \\
\text { impacts on health; } \\
\text { rewards. }\end{array}$ \\
& regulations. \\
\hline
\end{tabular}

In the remainder of this sub-section we examine a number of issues associated with market failures and government limitations which are of direct relevance for climate policy and costs of action.

\subsubsection{Limitations on government}

It should be obvious that government has not eliminated these market failures, or that even with the measures proposed, that it could. Moreover, the large intra- and intergenerational distributive effects of climate change typically are not undone by government. Nor has government engaged in redistributions to the point where the marginal social benefits of a dollar to each individual at each date is the same.

Formally, some of the market imperfections (including those associated with incentive compatibility, self-selection and collateral constraints) and limitations on government's ability to correct these and to redistribute could be introduced into the standard IAM optimisation problem by adding these as constraints in the associated Hamiltonian ${ }^{38}$. Positive shadow prices on such a constraint would indicate that the constraint is binding.

${ }^{38}$ For details, see Stern and Stiglitz (2021). 
More importantly, the consequence is that the shadow price associated with carbon (the SCC) will change. A world with such limitations is markedly different from one without, and policy will differ.

These limitations have multiple implications, some of which we explore in the remainder of this sub-section and the next on technology (5.2).

\subsubsection{Structural change and dislocation}

Action on climate change, both emissions reductions and adapting to the climate change which will occur, will embody large structural change in the economy. Analysing how best to manage these structural changes is indeed at the core of the green transition. Here we focus only on the methodological issues which arise from the fact that we are analysing structural changes, rather than the detailed analysis itself. We return briefly to these issues in the final section.

Markets do not, by themselves, handle well large structural changes, partly because pervasive capital and risk market imperfections imply that those whose assets have markedly decreased in value may not have access to resources that would enable them to transit into alternative, more productive uses. ${ }^{39}$

Structural transformations require coordination--the economy can be stuck in a "bad" equilibrium, in which case the social marginal cost of carbon can be markedly different (and higher) than it would be under a better trajectory.

Moreover, the overall economic system consists of a multiplicity of subsystems-energy, cities, land usage, transportation. To describe the radical and wide-ranging changes that will be necessary to move these systems to zero-carbon would take us beyond the scope of this paper. Here we note: non-convexities abound and such transformations require extensive coordination. But there simply are not the necessary full set of prices that would be

\footnotetext{
${ }^{39}$ Because of the pervasive market failures, including the macroeconomic externalities noted earlier, decisions by market participants on the pace of transformation are not in general (constrained) Pareto efficient.
} 
required, even in the absence of non-convexities. ${ }^{40}$ Achieving coordination within each system is hard enough, but the systems interact with each other. Transport, residences, and work places interact very powerfully. As a matter of method it would be a basic mistake to assume that the move to zero-carbon could be managed with just one price (Coalition for Urban Transitions, 2019). A multiplicity of interventions are required: in design, zoning, standards, regulation policy and so on. ${ }^{41}$

\subsubsection{Intragenerational effects}

As we noted above, climate change has large intragenerational distributive effects, which are not typically undone by redistributive policies. ${ }^{42}$ Any normative approach needs to take these into account. If climate change adversely affects poor individuals disproportionately (either because they experience more and stronger effects or have a lower capacity to cope), and there is no offsetting redistribution, then average future social marginal utility of income (consumption) will be higher (than it would be in the representative agent model, relative to current marginal social utility, along any given environmental trajectory)-implying the desirability of stronger climate change policies.

There is another important source of differentiation: that of individuals by place. There will be high variability in impacts of weather, not perfectly offset by compensatory payments from those areas that are less affected to those that are more affected. This implies (with any inequality averse social welfare function) that social welfare will be lower, and more

\footnotetext{
${ }^{40}$ In the presence of non-convexities, prices may not lead to (Pareto) efficient outcomes. This was one of the important insights of Arrow and Debreu which seems to have been ignored by IAMs.

${ }^{41}$ In Stern and Stiglitz (2021) we elaborate on the necessary changes to some of the systems that we have to be changed and the policies that might generate those transformations.

${ }^{42}$ The assumption that the government has engaged in optimal redistribution is clearly wrong: with a utilitarian-equalitarian social welfare function, incomes would be redistributed so all individuals had the same income. That the government undoes any distributive effects arising from climate change is also clearly wrong and to base normative conclusions about appropriate climate policy on that predicate is methodologically wrong. We know that the second theorem of welfare economics, relating Pareto efficiency to a competitive equilibrium, requires the right lump-sum transfers. Modern public economics has explained why these do not and cannot occur (Stiglitz 2019). The polar assumption, that government will do nothing, may be nearer the truth. A good normative approach would prescribe the climate action to be taken as a function of the redistributive actions undertaken by the government.
} 
affected by, climate change. Again, ignoring these spatial disparities results in a marked bias towards weaker action. ${ }^{43}$

There is a third basis of differentiation: among individuals similar in circumstances within any location (at any income level), there are "horizontal" differences that can sometimes play an important role in political economy, e.g. among those differing in sensitivity to climate change because of health conditions. Again, the social consequences of climate change, with reasonable social welfare functions, may be markedly greater than they would be if one ignored these horizontal differences. ${ }^{44}$ The examples of section 4 illustrated how large a difference incorporating these changes can make.

\subsubsection{Transition Risk}

Much of standard finance literature assumes that markets are forward looking, and they act as if they had fully rational expectations. But the hypothesis of fully informationally efficient markets has been subjected to extensive theoretical scrutiny and empirical testing, and has been widely rejected. ${ }^{45}$ In the case of climate change there is powerful evidence that the risks are very far from being fully embodied in markets ${ }^{46}$. Given that that is the case, the possibility, if action is delayed, of a disorderly financial transition, as the risk of climate change finally becomes generally recognised, cannot be ignored. A "disorderly" transition to a greener, sustainable economy would entail sudden changes in the price of carbon, resulting in sudden changes in asset values. Such changes can trigger a systemic crisis, with macroeconomic consequences that amplify the initial disturbance, as a result of macroeconomic externalities.

The cost of such a disorderly transition would be potentially very large, and the increase of costs as a result of not controlling carbon emissions should be viewed as part of the

\footnotetext{
${ }^{43}$ As we have noted, some IAMs do have differentiation across regions but this is usually at a very aggregated level.

${ }^{44}$ For more detail on the impact on the costs of climate change of introducing each complexity see Stern and Stiglitz (2021).

45 Grossman and Stiglitz (1980) established that if it were true, the only information that would be efficiently reflected in market prices would be costless information. Shiller (1981) subsequently provided a wealth of empirical information documenting the informational inefficiency of markets.

${ }^{46}$ See, for example, Stroebel and Wurgler (2021).
} 
marginal social cost of carbon-but they are not. The IAMs simply ignore the possibility of such imperfections. The consequences could be greatly mitigated if financial institutions and corporations had more limited exposures to carbon risk, and disclosure requirements and reflecting the risk in bank regulations would likely induce less exposure to carbon risk. ${ }^{47}$ Without such disclosure, it is impossible for private actors to take appropriate actions to limit and mitigate climate risk, enhancing the likelihood of a disorderly transition, and the market is likely to engage in excessive climate risk. While regulators in several countries, such as the UK and France, have already begun to recognise the need for disclosure rules concerning climate risk (one example of why rules matter), for many countries such rules may be a long time coming, and that would imply the likelihood of inadequate climate action for an extended period of time. ${ }^{48}$

Transition risk illustrates several of the themes of this paper: the desirability of the use of multiple instruments beyond carbon pricing and the likelihood, because of the associated market failures, that the societal costs of more aggressive climate action will have a net benefit substantially greater than that predicted by typical IAMs.

\subsubsection{Two broad and fundamental implications of incorporating market failures}

There are two broad and fundamental implications of incorporating market failures into the analysis. The first is, as we have noted, the costs of achieving any climate target may be far less than if the economy were fully efficient but for the climate externality, and the benefits may be larger, implying the desirability of more aggressive climate targets. Whilst, theoretically, market imperfections and missing markets can lead to overinvestment as well as underinvestment in green technologies, the market failures highlighted in Table 1 clearly tilt against investment in the transition to zero carbon. For example, the transition to zero

\footnotetext{
${ }^{47}$ Without appropriate government regulation there will not be adequate disclosure of risks (Stiglitz, 1975; Grossman, 1981). The recommendations of the Task Force on Climate-Related Financial Disclosures have been accepted voluntarily by many firms and will become mandatory in the UK from April 2022.

${ }^{48}$ Even if current governments adopted good climate disclosure rules, there can be significant transition risk. Climate action depends significantly on public action, and that in turn depends on the not-fully-predictable outcome of elections. An election of a "green government" would thus give rise to a "jump" in future expected climate action, with all the systemic effects of a disorderly transition described above. The consequences could be greatly mitigated if financial institutions and corporations had more limited exposures to carbon risk.
} 
carbon will be particularly R\&D intensive; it will be particularly dependent on networks; many green investments are capital intensive, and capital market imperfections limit the ability of households, small companies, and poor countries to make what would otherwise seem to be efficient investments; and the co-benefits of phasing out fossil fuels for health are very strong.

Secondly, when there are multiple market failures, it is in general desirable to employ a multiplicity of interventions, not just a carbon tax. ${ }^{49}$ Table 1 has illustrated a rich set of desirable interventions, involving pricing, information, regulations, and public investment. Action on one of the failures can reinforce action on others; these cross-effects should be studied and utilised. ${ }^{50}$ Policy recommendations derived from IAMs which point to a dominant focus on price interventions are simply a result of the extreme assumptions employed.

\subsection{Technological change}

The technologies we use for our activities will look fundamentally different in a zero-carbon world. We can already see some of the technologies we will have to use, for example, for renewable energy. Others, for example those associated with use of hydrogen or zerocarbon fuels for air travel, are in their early stages and we will have to seek more; technologies for cement and steel have to change. We can already see elements of effective technological responses emerging.

Because innovation is central to the response to climate change, and because the presumption is that the rate and direction of private investments in innovation is not socially efficient (see, e.g. Stiglitz and Greenwald, 2014), methods and models which assume that the only market failure is that associated with emissions are inherently limited. If it is possible to foster innovations which lower emissions at relatively low costs, then the costs

\footnotetext{
${ }^{49}$ A large literature focusing on imperfect information, incomplete markets, and limited redistributive tools has shown that interventions beyond simple corrective taxes are desirable (see, e.g. Atkinson and Stiglitz, 1976; Stiglitz, 2018; Weitzman, 1974). The relevance of these concerns in the context of climate change has been emphasised by Stern $(2007,2015)$ and Stiglitz (2019).

${ }^{50}$ In the context of innovation, discussed in the next section, see Acemoglu et al. (2012).
} 
of achieving any target will be greatly lowered relative to an analysis which pays little attention to the processes of investment in and policy towards innovation. New growth opportunities will be generated. By assumption, that is not the case in standard IAMs. We have already seen very strong technical progress on the back of fairly modest policy ${ }^{51}$. Strong policy across a number of market failures which affect the rate and direction of innovation and the diffusion of knowledge, employing multiple policy instruments, could greatly accelerate the pace of change, enabling the achievement of climate targets at much lower costs. And there are likely to be further macroeconomic and other societal benefits from the induced innovation.

\section{Intertemporal trade-offs and risk in shaping climate policy}

\subsection{Centrality of methodology}

Climate change represents a special set of social decisions: the current generation is making decisions which affect future generations, indeed could put their welfare at great risk. Since those generations are not here to express their voice, the issue of societal decision-making is unavoidably moral/ethical. These issues must be examined directly and cannot, as a matter of methodology, be avoided, for example by trying to look for answers in markets. They are embedded in the "logic of the problem".

Discounting is about valuing changes in welfare of future generations. Thus the combination of risk and discounting, and their assessment, lies at the heart of decision-making on climate change. The two are inseparable, and one of the limitations of the IAMs is that they ignored the centrality of risk.

This section examines how to understand and model the combination of risk and discounting, with an emphasis on the critical role of methodology.

${ }^{51}$ See, for example, Systemiq (2021). 


\subsection{Ethical perspectives}

In economics, standard approaches to ethical questions have embraced consequentialism and the use of explicit utility (social welfare) functions. In Stern (2015, chapter 6 and 2014a, b), approaches from other perspectives on moral philosophy to the economics of climate change are examined, including Aristotelian (or virtue ethics), Kantian (categorical imperatives), social contractarian, and liberty, justice and rights in the tradition of Isaiah Berlin and Amartya Sen. This is not the place to examine in detail the role of these perspectives in relation to action on climate change; we touch only on a few themes related to the central objective of this paper.

The Aristotelian approach asks not "what ought we to do?" but rather "what sort of person should I be?". It emphasises the role of moral character, or "virtues," in living an ethical life. Kant's "categorical imperative" gives a criterion for the judgement of moral behaviour in oneself or others. Essentially, it invokes the notion of "duty" and examines its bases. Contractarianism grapples with the question of "what is the nature of the social contract?" and, in particular, in this context "what is the nature of the social contract with those not yet born who could not be present to participate in the contract, unless we act on their behalf?". Perspectives in political philosophy concerning liberty, rights, responsibilities, and justice relate to the liberty or freedom individuals should have to take decisions as they would wish, in relation to what they desire or value, and in relation to the effects these decisions might have on others.

Further, at least from the Justinian code on, the public interest doctrine has held that the sovereign (the state) holds natural resources (here the environment) as a fiduciary, in trusteeship or stewardship for future generations. Even if on average future generations are assumed to be much better off than the present, a course of action which would entail some chance of extreme adverse climate impacts on future generations, if those impacts could have been avoided by a modest expenditure of resources today, could be seen as a violation of that principle. ${ }^{52}$

\footnotetext{
${ }^{52}$ Rawls (1971) can be read as supporting this perspective. It is especially consistent with utility functions in which the environment explicitly enters into utility functions and is imperfectly substitutable with conventional consumption goods.
} 
Many dimensions of the different ethical perspectives have not put risk at centre stage and risk, particularly extreme risk, intensifies and deepens the moral arguments. Nevertheless, from the different perspectives of all these arguments, actions that could put the lives and livelihoods of hundreds of millions at great risk would be seen as immoral. A just society would avoid such actions ${ }^{53}$. An economic calculus (e.g. as described in section 2 ) which leads to conclusions inconsistent with what a just society would do has obviously left out something(s) important and crucial. This paper has identified critical missing elements in the standard IAM. For instance, by ignoring key aspects of risk, by assumption, it cannot address the immensity of risks imposed on future generations. Section 3 provided a critique of those implementations of the model which do incorporate risk through a standard expected utility analysis. There are others: the standard approach does not adequately differentiate attitudes towards risk from intertemporal preferences, in the way Epstein-Zin (1989) preferences do. ${ }^{54}$ One should not assume that utility functions used to model intertemporal allocations are necessarily the same as those that are appropriate for modelling behaviour towards risk.

The remainder of this section ignores the critiques based on deep uncertainty and extreme risk, focusing instead on the basic concept of discounting, which has often been muddled, implications of imperfect risk and capital markets and limitations on government redistribution highlighted in the last section.

\subsection{Discounting}

Decisions now on climate action affect the welfare of those in the future. A consequentialist analysis inevitably faces the question of how to value costs and benefits in the future relative to now. Discounting-how we value a dollar in the future relative to a dollar today-is important. Some, such as the Trump Administration in the US, have argued that the

\footnotetext{
${ }^{53}$ We are using a broad notion of justice here, which could be linked to a number of the perspectives just described. See, e.g., Sen (2009) for an enlightening explanation of justice. He focuses on injustice in terms of depriving others of rights or entitlements. In this context it would be depriving or severely restricting the rights of future generations to development.

${ }^{54}$ See also Kreps and Porteus (1978).
} 
appropriate discount rate is around 7\%, implying that an increment of income five decades from now would have a weight of $3 \%$ relative to now. This would point to low SCCs and weak climate action.

For marginal increases the central concept is the social discount factor, which is the value or weight attached to an increment of a good in the future relative to now. The social discount factor is essentially a relative shadow price, a core concept throughout economics. Much of the discussion of discounting has been confused by jumping straight to the discount rate which is the proportional rate of fall of the discount factor.

We emphasise that it is the discount factor that is the logically prior concept. Indeed, starting with the social discount factor makes it clear that we cannot discuss it, and the discount rate, coherently without reference to future standards of living and the threat to these living standards from climate change. Most value judgements about relative weights to increments in consumption or income for different people would focus on their relative living standards.

Accordingly, we need to focus on future living standards; and pure-time discounting ${ }^{55}$, the relative value of a life in the future relative to a life now, as the key determinants of social marginal utility. These are readily understandable concepts which are reflected in public discussion and the values behind those discussions. In the context of IAMs we should recognise that in implementing this approach we cannot sensibly impose an exogenous long-run growth rate when climate change can have such catastrophic results.

It is clear that the relative shadow prices embodied in discount factors will depend on time, the state of the economy and climate, which individuals or groups are involved, which goods and so on. To speak of the discount factor or rate with over emphasis on the definite article is to misunderstand the concept and problem. There are several alternative approaches.

\footnotetext{
${ }^{55}$ We have offered our views already on pure-time discounting.
} 


\subsubsection{Social discounting, market rates of interest, and intellectual consistency}

Some have tried to point to the capital markets for answers. But, even if markets were perfect, in the absence of optimal intertemporal redistribution, there is no relationship between market rates of interest and the relative marginal valuation of a dollar at different dates (to different generations). Observed market rates of interest reflect only the intertemporal trade-off of the current generation, not societal trade-offs across generations. Observing one does not allow us to infer the value of the other.

Of course, if one were to take the IAM seriously, ignoring risk but assuming optimal intergenerational redistribution, then the observed intertemporal discount rates would be low-in recent years close to zero (the safe real interest rate)-far lower than the numbers typically used in implementations of IAMs. Calibrations of the model cannot, of course, ignore risk and market imperfections, setting the stage for an inevitable intellectual inconsistency. Later, we explain how incorporating risk correctly implies an even lower discount rate than commonly assumed in relation to IAMs.

\subsubsection{Using the Ramsey model}

We can illustrate the approach which begins with the social discount factor by linking with the simple Ramsey model.

Generally, the value $\lambda$ of an increment in consumption in the future (relative to now) would depend on the good itself (indexed $i$ ), to whom it goes (indexed $h$ ), the time it occurs (indexed $t$ ) and the state of nature (indexed $k$ ). To keep things simple, we focus for the moment on time and an aggregate consumption good, noting that that leaves out risk and any direct effect of climate change on well-being (i.e. its only effects are through impacts on consumption).

The social discount rate is defined as the proportional rate of fall of $\lambda$. If we define $\lambda$ as the social marginal utility at time $t$, we have ${ }^{56}$,

\footnotetext{
${ }^{56}$ We emphasise the strong restrictions implied in this, the standard formulation: utility functions that are additively separable. Later, we introduce an environmental variable.
} 
(8) $\lambda=u^{\prime}(c) e^{-\delta t}$

and

(9) $-\dot{\lambda} / \lambda=\eta g+\delta$

where $\eta$ is the elasticity of social marginal utility of consumption (and could depend on the level of consumption), $g$ is the growth rate of consumption (per capita) and $\delta$ is the puretime discount rate ((9) is often described as the Ramsey equation). It is important to recognise that $g$ and possibly $\eta$ are endogenous variables. If climate change causes negative growth, this discount rate could be negative. Thus, no analysis of appropriate climate policy can begin by taking the discount rate as given. Moreover, we argued earlier that the only ethically defensible value of $\delta$ is zero ${ }^{57}$.

The shape of the utility function is captured in this framework through the parameter $\eta$. There is a substantial literature which tries to infer $\eta$ from individual and social choices (Dasgupta, 2008; Barro 2013). However, as Atkinson and Brandolini (2010), and Stern (1977) have shown, attempts to infer $\eta$ from allocation decisions of governments give answers which range from negative to very high. Similarly, attempts to infer $\eta$ and $\delta$ from savings rates depend crucially on assumptions about individuals' beliefs about the pace of technical progress. There are also multiple problems in trying to infer $\eta$ from behaviour under uncertainty (including the fact, observed earlier, that in general, attitudes towards risk may differ from those associated with intertemporal allocation). If we are to use this formulation, we need to consider a range of specifications for $\eta$. For instance, median real income per household in the US has increased at a rate slightly less than $0.5 \%$ over the past two decades, though more recently it has been increasing much more slowly. Using that as a proxy for the rate of increase in consumption and assuming $\eta \approx 1$, then the discount rate is $0.5 \%$; if $\eta \approx 2$, then it is $1 \%$.

${ }^{57}$ With the usual qualification on the probability of the "end of the world". 
If climate change has a direct effect on well-being (as it almost surely does), so we write $\mathrm{U}=\mathrm{u}(\mathrm{C}, \mathrm{E})$, and a deterioration of the environment decreases the marginal utility of income (as it plausibly would), then the discount rate will be still lower.

\subsection{Combining risk and discounting}

Both risk and discounting play a strong role in decision-making around climate change. We need to combine assessments of the nature and consequences of risk and valuations of future changes associated with climate change.

There was a lively debate (Dasgupta, 2007; Nordhaus, 2007; Weitzman, 2007) after the publication of the Stern Review in 2006 of the relative importance of these two elements. This eventually pointed to the fairly obvious conclusion that both matter. This is encapsulated in the theorem presented in the box below, which is adapted from Stern (2008):

\section{Role for Both Risk and Time in Intergenerational Welfare Analysis}

- Write the difference in the expected utility with and without climate change as $\int_{0}^{\infty} g(t) f(t) d t$, where $g(t)=E[\Delta u]$, and $\Delta u$ is the difference at time $t$ in welfare with and without climate change; is the pure time discount factor. $g(t)$ will depend on model structure, policies/path, and shape of $u(c)$. It is possible that $g(t)$ is infinite for some finite $T$ (see Weitzman 2007a).

- For any given $g(t)$, we can construct $f(t)$ so that $\int_{0}^{\infty} g(t) f(t) d t<\varepsilon$ for any $\varepsilon>0$, i.e. there are arbitrarily small losses from climate change. An example is $f(t) \equiv$ $(1 / g(t)) e^{-\delta t}$ with $\delta>1 / \varepsilon$.

- For any given $f(t)$, we can construct $g(t)$ so that there are infinite losses from climate change, i.e. $\int_{0}^{\infty} g(t) f(t) d t=\infty$. An example is $g(t) \equiv 1 / f(t)$.

- Clearly, both risk and time can play key roles in welfare judgments.

Note to box: (1) The box illustrates that even with time discounting, if the risks of welfare losses from climate change increase fast enough, expected utility with climate change will not be defined (effectively, minus infinity), so that if it is feasible to avoid it, one should. To make the argument as simple as possible, we have assumed a time additively separable utility function; obviously, the result is more general.

The argument in the box is essentially as follows. For any set of damages in the future, there is an approach to discounting which makes their social valuation as small as we please. And 
for any pattern of discounting, there is a set of climate risks which makes damages as large as we please. Both risk and discounting can be important. ${ }^{58}$

However, the arguments presented in the previous sub-section and in sub-section 3.5 imply that it is hard to ethically defend high discount rates. And the arguments presented in section 3 imply that in the presence of deep uncertainty and extreme risk, the expected utility framework simply does not work. And we should emphasise that as the science advances and concentrations increase (see, for example, IPCC, 2021), the gravity of the risks and the importance of deep uncertainty and extreme risk become ever clearer.

Assume, though, that risks are sufficiently limited and well-defined that the standard expected utility framework were acceptable. Within that framework, what can we say about the appropriate discount rate? Suppose also that we put to one side the problems we have raised about the relationship between market behaviour and social values. This is, of course, to ignore basic fundamentals, but what might we find if we pursued that route?

To a first approximation, the answer is remarkably simple: whether the discount rate is lower than the "safe rate" depends on whether the expected marginal utility of income is falling faster than the marginal utility of expected income. In the context of limited and well-defined risks, in which the expected utility model works, there is a strong presumption that incorporating both risk and uncertainty leads to a discount rate below the (real) safe rate of interest-which recently has been very low, less than $1 \%$, even negative. ${ }^{59}$ There are three reasons for this simple answer:

a) Negative correlation between returns to climate mitigation investments and marginal utility of income (Arrow et al., 1995).

Such investments pay off especially when climate change is worse than expected, in which case societal well-being will be low, and the marginal utility of income high. Climate investments provide a form of partial insurance. Just as investments whose

\footnotetext{
${ }^{58}$ Note that whilst the box illustrates $g(t)$ via the expectation of utility, the approach through $g(t)$ and $f(t)$ is more general than that.

${ }^{59}$ We should reiterate what we noted earlier: the deterioration of the quality of the environment may increase the marginal utility of consumption.
} 
returns are positively correlated with income require a return in excess of the safe return, it is desirable to make investments with a negative correlation even when the returns are less than the safe rate of return. ${ }^{60}$

The fact that the average return to capital is, say, 7 percent is not an argument for using a 7 percent discount rate in climate change. ${ }^{61}$ To blithely discount future streams of revenues and expenditures (net profits) at a higher rate when there is greater private risk, is to confuse social time discounting with private risk discounting. The failing of such an approach is reflected in what it would imply about responding to an increase in the uncertainty associated with a future liability (cost), such as those from the clean-up of a nuclear power plant. Greater uncertainty would imply (in the standard methodology) a greater discount rate, so that we should pay less attention to such costs, the greater the risk.

b) The risks that the firm looks at are its private risks, which are distinctly different from those of society as a whole. There is no reason that the appropriate compensation for risk for a typical private investment-which includes, for instance, the risk of bankruptcy-- has anything to do with that for a climate investment.

c) Increasing risk over time justifies using an interest rate that is lower than the safe interest rate, simply because the increasing risk (normally) leads to an increase in the expected marginal utility of income. ${ }^{62}$

\section{Ways forward}

\footnotetext{
${ }^{60}$ Heuristically, in the presence of time separability of utility we can calculate the certainty equivalent of expected utility at each date, and to use that to assess discounted welfare and the marginal social value of a dollar in the future. For more on the certainty equivalent level of consumption and the implications for climate change mitigation, with risk, see Stern \& Stiglitz (2021).

${ }^{61}$ Some have argued for using the $7 \%$ discount rate because it represents the opportunity costs. But the opportunity cost for a safe investment is the safe rate of interest, which is very low. The difference between that and the observed $7 \%$ return on capital is the compensation for private risk and/or monopoly returns. 62 If there is increasing uncertainty about the consequences of climate change going out in time, then the certainty-equivalent of future generations' income (as viewed today) is increasing more slowly than the average (or expected) consumption level-indeed, if risk is increasing enough, it may be decreasing; and the expected marginal utility of income at future dates is accordingly higher. This means that we would want to take stronger precautionary actions today. (This is a heuristic analysis; a fuller analysis is more complicated, with results depending more sensitively on the shape of the utility function.)
} 
The problem with IAMs

It was understandable that early analyses of responses to climate change involved the application of standard workhorses of economics- simple exogenous growth theory-- to a problem new to economists, by assuming marginal perturbations for climate change and increasing marginal costs of action. But over time, here (as in macroeconomics, where another variant of the Ramsey intertemporal maximisation model became the workhorse model), the deficiencies in the underlying model, including those delineated throughout this paper, made clear its limited usefulness in addressing the core questions for which it was constructed, in particular in relation to the ever-growing understanding of the potential immensity of the risks. The scale of those risks takes us outside the case of these standard workhorses.

Unfortunately, many in the economics profession did not appear to recognise the limitations of this framework either in their work or in public debates. The advocates and practitioners of IAMs seemed to want to argue, or give the impression, that their approach was the way to analyse policy. The result was a chasm between the policy recommendations of the majority of those economists using variants of these models and the rest of the scientific community. This paper has sided strongly with the latter, which has rightly focused on the possibilities - or probabilities_of extreme and unacceptable outcomes occurring on the economists' "preferred" trajectory which emerges from many of the IAMs.

Some might argue the problem is not with the methodology itself but with particular implementations (see e.g. Aldy et al., 2021). We have seen, for instance, (see section 4) that when some of the objections we have raised are addressed, for example, better, more comprehensive damage functions (reflecting, e.g. non-linearities, impacts on lives, health, biodiversity, and distribution, and paying some attention to risk and variability) or greater attention to intra-generational distributive effects or incorporating market failures better, or more realistic treatments of cost functions and technical progress, the results change radically and move closer in their "optimal" trajectory towards the recommendations of the 
scientific community. But, at the same time, the great sensitivity of results to model specification that this work demonstrates undermines the usefulness of the approach.

Our objection is not just to the lack of robustness of the standard IAMs, or even the biases built in the results by the particular assumptions made in the most widely cited implementations which generate the "optimality" of 3 to 4 degrees Celsius. In our view, it would be a mistake to argue that whilst IAMs are not yet ready for prime time - for being at the centre of policy discussions - with diligent work continuing the advances of the last quarter century, they will be. Those advances have been substantial, and more plausible versions of the model have, as we have noted, at last generated results that seem consistent with the decisions being made by the international community. The more fundamental problem is that these models are not well suited to analysing problems of deep uncertainty, extreme risk, endogenous preferences, intergenerational equity (where future generations are not discriminated against), and increasing returns to scale and rapid technological change.

Even "new and improved" IAMs are likely to be of only limited value in providing policy guidance for several reasons-- and that will continue to be true even as more information becomes available as to the nature of climate change and the policies and actions that might tackle it. First, even if we make the assumptions more realistic, these models have been shown to be very unrobust; they are not helpful for guiding policy decisions, unless we are very confident in all of the key functions and their parameters-which we cannot be. Here, though, the models, perhaps unintentionally, have proven their usefulness in another way, by highlighting some of the variables, like risk and distribution, which are critical. To be sure, any theoretical analysis would have given the same results, at least qualitatively.

Second and equally important are the normative issues discussed in section 3: critical are (a) the magnitudes of risk associated with different concentrations of greenhouse gasses; (b) our willingness to accept imposing those risks on future generations; and (c) the deep uncertainties-we know that we don't know. This is where the public dialogue should be 
and - with the exception of some economists focusing excessively on IAMs-has been. The framing of the critical issue as being one just of intertemporal trade-offs is misguided. ${ }^{63}$

Finally, the IAMs are silent on what has become a major motivation for change, the realisation that action on climate can lead to a whole new approach to growth and development which can yield paths which are more dynamic and attractive than the dirty growth that has gone before. The implicit assumption of IAMs that markets work so well that if those opportunities were really there, they would have already been seized is based on presumptions about market efficiency (other than in the arena of climate) that are unpersuasive. It is the understanding that these new opportunities are there that has led to change in policy approaches in many countries.

\section{Exploring a variety of models}

Accordingly, for economic analysis to help inform us about the answers to the critical policy issues posed by climate change necessitates using a set of models and analyses which look very different from IAMs. There are a variety of alternative approaches that are likely to provide better guidance for policy makers. There are several key questions, and a model designed to help answer one may be less helpful in answering others. Among the key questions are: what should be our climate targets? What instruments should we utilise? If we use prices as guidance, what is the social cost of carbon? What are the large structural changes that will be required as part of the green transition? How can we foster the innovation and investment that can lead us to a new path of sustainable, resilient and inclusive development and growth?

Addressing the full set of policy challenges presented by climate change will require a collection of conceptual, theoretical, empirical and modelling approaches and not just a single grand model. We hope that our paper will be of use not just as a critique of IAMs and

\footnotetext{
63 To put it another way, there is no way that an advocate of the IAM claiming that the international community is making the wrong decision in limiting excessively carbon emissions can invalidate preferences saying that it is unacceptable not to do what we can to avert the risks associated with 3.5 or 4 degrees Celsius temperature change. Saying that there is a world without deep uncertainty and extreme risk where some individuals would reject paths entailing the levels of curbing emissions required to achieve 2 degrees Celsiusthe only world that they investigate-- does not establish that it is in any sense "irrational" for society to adopt the 2 degree target in the actual world marked by deep uncertainty and extreme risk.
} 
a warning against taking them too seriously for policy guidance, but in helping set the research agenda going forward: understanding the limitations of IAMs is important if we are to develop approaches that are more useful for policy purposes.

We have suggested that key in setting the targets are models that focus on deep uncertainty and extreme risk, identifying, for instance, points of large non-linearities and assessing approaches, with their investments and costs, of averting the worst outcomes. This is central to what we have identified as the guardrail approach. There would be great value in deeper analytical and philosophical analyses of decision-making in the presence of extreme risk and deep uncertainty. Can we throw further light on how to portray and understand decisions about catastrophes of different nature and scale? We would hope to both tackle and go beyond the analytical problem of "minus infinity". There are different orders of infinity and various possible approaches to uncertainties. This is likely to be deep and difficult work, but it is important.

As we emphasised in the introduction, the international community has made a judgement that the risk associated with temperature changes in excess of 2 degrees Celsius are unacceptably high and have set targets of "well-below 2 degrees" or $1.5 .{ }^{64}$ Increasingly, the target is 1.5 degrees Celsius as the risks of 2 degrees Celsius are better understood. That decision was made with full knowledge of the results of IAMs. The "guidance" of the IAMs was forcefully and rightly rejected: IAMs simply did not address the risks which were central to that collective decision. ${ }^{65}$

Having "solved" the problem of defining targets, the economics of policy should focus on how to achieve them in the best way possible. For assessing alternative trajectories consistent with that goal, a first approximation--far more relevant than standard IAMs (but in one sense, a natural development of the IAMs)--are models that take that goal, e.g.

\footnotetext{
${ }^{64}$ As in the Paris 2015 agreement. And, as we have remarked, many countries have now declared for 1.5 degrees Celsius given the perceived danger of 2 degrees Celsius.

65 Moreover, for all the reasons that we have articulated in this paper, the conclusions of the IAMs were biased. But, as we have noted in section 1, the IAMs have nonetheless been used to influence public discussion and, extensively and misleadingly, in calculations of SCCs.
} 
expressed in terms of temperature change, as a constraint and ask what is the best way to achieve it. Such an approach keeps the acceptable level of risk in bounds.

We have explained why the standard IAMs provide inadequate guidance not only about the targets, but also about how whatever targets should be best be achieved. They argue for reliance on price interventions. We have explained why it is desirable to use multiple instruments, and why the desirable SCC is much higher than that which emerges from the standard IAM.

There has been some work (e.g. Kaufman et al., 2020) that places constraints on emissions or temperature within an IAM framework. Interestingly, this work, centering on one of the key problems with IAMs that we have identified, yields a SCC that is far more in accord with that of Stern and Stiglitz (2017) than that associated with the standard IAM-or to put it another way, accepting the SCC of the standard IAMs would lead to carbon concentrations and climate change at a level far beyond that of the international consensus. ${ }^{66}$

The longer-range research agenda will need to address the multiple limitations of the standard IAMs to which we have called attention. We note, however, that the incorporation of the constraints described above in the guardrail approach implies that the biases introduced by those omissions will have more limited consequences, so that methodologically, we should have far more confidence in the policy recommendations.

Because risk is central to the analysis of climate, we will need to investigate stochastic optimisation models. And because we know that we will learn much more about climate risk

\footnotetext{
${ }^{66}$ We note other heuristic approaches designed to give first-order approximations, without embarking on the full sequential stochastic optimisation (see below). For instance, to capture the greater precautionary behaviour warranted by the possibility of more extreme outcomes, some model that the economy and environment as if they were described by a particular (known) set of "extreme" parameters. In a world with risk aversion and strong non-linearities in the relevant functions, focusing on the $95^{\text {th }}$ percentile may provide far better guidance for policy than focusing on the mean of the scenario analyses. Interestingly, in at least some variants of IAMs, doing so (even with their other flaws, e.g. concerning discounting, discussed above) yields a social cost of carbon and corresponding climate targets that are much more in accord with those advocated by the rest of the scientific community. Still, even then, this approach may not adequately capture the nature of the optimal trajectory when there is uncertainty about the value of the parameters, e.g. because it does not adequately reflect irreversibilities and the possibility that there could be catastrophic outcomes far worse than that reflected in the " $95^{\text {th }}$ percentile".
} 
and about methods for finding alternative and sustainable paths for growth and development, models employing sequential decision making will be of real interest (e.g. Keller, et al., 2004; Lemoine and Traeger 2014; Diaz \& Keller, 2016; Lontzek et al. 2015; Cai et al., 2016; Lemoine \& Traeger, 2016).

This does not mean that each model should try to capture everything. On the contrary, each one should focus on a key issue or issues, remembering in each case Rodrik's dictum (2015, p.213): "Unrealistic assumptions are ok; unrealistic critical assumptions are not ok". We should emphasise strongly that we will need a range of models and analytical approaches. Any choice of a particular model or analytical approach involves choices between specificity and generality. Some will be more specific, for example, around disclosure in financial markets or the fostering of innovation in the energy sector. Others will be more general, including at the theoretical level, for example, to make the point about extreme risk and deep uncertainty in relation to guardrails.

A key element will be to construct better underlying descriptive models. Between them they should examine relevant market failures, including those associated with technological progress, more realistic modelling of the behaviour of individuals and firms, and the criticality of institutions, particularly in the context of systemic change. We should have an open mind about what kind of models and analytical approaches will help answer key policy questions. ${ }^{67}$

Behavioural economics may provide insights into how to encourage individuals to use lower emission technologies or to eat lower emission foods; such interventions often entail low costs, enabling climate targets to be achieved at much lower costs than otherwise would be the case.

\footnotetext{
${ }^{67}$ Farmer et al. (2015) argue that agent-based models (ABMs) have the potential to address some or most of the failings that they identify in the current generation of models. There are always trade-offs in modelling. While such models enrich the diversity of agents (obviously from that in the standard representative agent model) and break away from the stringency of behaviour dictated by intertemporal utility maximisation, critics argue that the behaviour modelled is sometimes too untethered to any sense of rationality, too ad hoc, too subject to the Lucas critique.
} 
Meeting the climate challenge will require large structural transformation, and standard aggregative models are of only limited use in guiding such transformations. ${ }^{68}$ In the absence of other market failures and non-convexities - key assumptions in the standard modelsetting the right prices can guide the economy to make the "right" allocations. But even apart from market failures like capital market imperfections and the incompleteness of risk markets, making the green transition will require complex changes in the economy's subsystems, which are marked by notable non-convexities and market failures. Acting on climate requires changing the large, complicated and interacting systems which generate a major part of economic activity, including, in particular, cities, land and natural capital, energy, and transport. ${ }^{69}$ Contrary to the implication of standard IAMs, we cannot expect the transformation of the whole economy-and especially key complex systems-- to be delivered by prices alone or even two policy instruments, or to be satisfactorily informed only by marginal analysis. Change will require coordination of a kind beyond that typically provided by prices (Stiglitz, 2018). It would thus be wrong to assume not just that there are no market failures, but that markets on their own would manage the necessary transformations efficiently.

Institutional structures are of the essence both in managing uncertainty and expectations and in system change. Institutional economics will have a central role to play in this collection of approaches. For instance, additional regulatory mechanisms will be needed to incentivise storage and flexibility in power systems (ETC, 2021). Aggregative models are obviously not well-suited for studying structural transformations and the policies that can best foster them; we will need detailed modelling of each of the key sectors, including the investments, regulations, and price guidance that will most effectively bring about the required transformations in a timely way.

\footnotetext{
${ }^{68}$ An important part of the structural transformation will be sectoral reallocations. A set of models that has been of some usefulness in some areas in analysing such reallocations are computable general equilibrium models. We are not sanguine that such models will be of much use in this arena. They have been most successful in analysing reallocations in economies that are highly competitive, without risk and especially endogenous innovation, and without important non-convexities, all features that we have suggested are central to the green transition.

${ }^{69}$ For work on cities, see, for example, the Coalition for Urban Transitions (2019 \& 2021); for land, see, for example, the Food and Land Use Coalition (2019 \& 2021).
} 
So too, given the key role of market failures as impediments to a fast green transition, we will need models that focus, for instance, on tackling pervasive market failures in the financial sector, e.g. imperfections in information, through disclosure requirements and central banks analysing carbon risk in all of its dimensions; imperfections in risk markets, e.g. by governments taking a role in de-risking climate investments; and imperfections in financial institutions, e.g. by the creation of green development banks. Tackling these market failures can substantially lower the cost of bringing about the transition (thereby impacting both optimal trajectories and the SCC).

These modelling advances will necessarily involve assembling microeconomic, structural, technological, and macroeconomic analyses of change for countries and communities across the world, accounting for the circumstances, difficulties and opportunities they face. This must involve a whole range of economics, working with science, technology and other social sciences and even humanities, as we have to address some of the ethical issues noted in this paper. ${ }^{70}$ The work will involve bringing the best of economic analysis to the table, including around innovation, behaviour, political economy, and growth and development, which will all be central to change.

We think that this paper is helpful for the necessary research because: (1) it provides a meta-perspective in the sense of looking at the relationship between models and their uses and the challenges that climate analysis and policy pose; (2) it shows the limits, contributions and developments of the dominant modelling framework; (3) it exhibits why we need a diversity of models and frameworks; and (4) it presents a way to approach to current pressing problems, including the guardrail approach and the analysis of systemic change in imperfect economies.

This paper thus provides a path towards the reconciliation between the perspectives of the broader scientific community, which has pushed for urgent and strong action (IPCC, 2018; Ripple et al., 2020) and a part of the economics community, using particular versions of

\footnotetext{
${ }^{70}$ In particular, we have noted the limitations in existing individual and social decision making frameworks in the presence of deep uncertainty and extreme risk. Methodological advances in this arena would be particularly helpful.
} 
Integrated Assessment Models, who have been sceptical of the need for such urgent action and have not only been tolerant of, but urged the acceptance of, higher levels of climate change. The intuitions of the scientific community may well be right: the simplistic models of the economists have simply not captured essential aspects of the societal decision problem. The answer will not be in terms of tweaking or refining existing IAMs but in developing a whole range of models, analyses and approaches to guide us on climate targets and on the structural change and new forms of growth and development that can best achieve them.

\section{An optimistic note}

We want to end this paper on a more optimistic note. Much of this paper has focused on the downside risk, the deep uncertainties associated with climate change, and possibilities of catastrophic outcomes if we fail to take adequate action. But the very market failures to which we have called attention imply that there is an upside potential to addressing climate change-one which too suggests the desirability of greater climate action. There is the potential of finding a new, cleaner, more efficient and more attractive form of growth, with better health and less pollution, in which case the apparent "costs of action" may turn out to be negative. In this sense, for many parts of the story of transition we should think of action in terms of investment and innovation rather than cost. The successes in innovation in the past decade suggest this optimistic scenario may not only be a possibility, but perhaps a probability.

\section{References}

Acemoglu, D., Aghion, P., Bursztyn, L., \& Hemous, D. (2012). The Environment and Directed Technical Change. American Economic Review, 102(1), 131-166.

Aldy, J.E., Kotchen, M.J., Stavins, R.N., \& Stock, J.H. (2021). Keep climate policy focused on the social cost of carbon. Science, 373(6557), 850-852.

Arrow, K.J. (1951). Social Choice and Individual Values. Wiley.

Arrow, K., Cline, W.R., Maler, K.-G., Munasinghe, M., Squitieri, R., \& Stiglitz, J.E. (1995). Intertemporal equity, discounting, and economic efficiency. Climate Change 1995 Economic and Social Dimensions of Climate Change. Contribution of Working Group III to the Second Assessment Report of the IPCC. 125-144. 
Ascari, G., Magnusson, L.M., \& Mavroeidis, S. (2021). Empirical evidence on the Euler equation for consumption in the US. Journal of Monetary Economics, 117, 129-152.

Atkinson, A.B., \& Brandolini, A. (2010). On Analysing the World Distribution of Income. World Bank Economic Review, 24, 1-37.

Atkinson, A.B., \& Stiglitz, J.E. (1976). The Design of Tax Structure, Direct versus Indirect Taxation. Journal of Public Economics, 6 (1-2), 55-75.

Barro, R. (2013). Environmental Protection, Rare Disasters, and Discount Rates. Working paper, Harvard University.

Budolfson, M., Dennig, F., Fleurbaey, M., Siebert, A., \& R.H., Socolow (2017). The comparative importance for optimal climate policy of discounting, inequalities and catastrophes. Climatic Change, 145, 481-494. https://doi.org/10.1007/s10584-017-2094-x

Cai, Y., Lenton, T.M., \& Lontzek, T.S. (2016). Risk of multiple interacting tipping points should encourage rapid CO 2 emission reduction. Nature Climate Change, 6(5), 520.

Carleton, T.A., \& Hsiang, S.M. (2016). Social and economic impacts of climate. Science, 353, aad9837.

Carroll, C.D. (2000). Requiem for the Representative Consumer? Aggregate Implications of Microeconomic Consumption Behavior. American Economic Review, 90 (2), 110-115.

Chichilnisky, G., Hammond, P., \& Stern, N. (2020). Fundamental utilitarianism and intergenerational equity with extinction discounting. Social Choice and Welfare, 54, 397427.

Ciscar, J.C., Rising, J., Kopp, R.E., \& Feyen, L. (2019). Assessing future climate change impacts in the EU and the USA: insights and lessons from two continental-scale projects.

Environmental Research Letters, 14, 084010.

Climate Action Tracker (2021). Glasgow's 2030 credibility gap: net zero's lip service to climate action Wave of net zero emission goals not matched by action on the ground. https://climateactiontracker.org/documents/997/CAT 2021-11-09 Briefing GlobalUpdate Glasgow2030CredibilityGap.pdf

Climate Watch (2021). NDC Enhancement Tracker. https://www.climatewatchdata.org/2020-ndc-tracker.

Coalition for Urban Transitions (2019). Climate emergency, urban opportunity: how national governments can secure economic prosperity and avert climate catastrophe by transforming cities. World Resources Institute (WRI), Ross Centre for Sustainable Cities and C40 Cities Climate Leadership Group, London, UK.

Coalition for Urban Transitions (2021) About us. https://urbantransitions.global/about-thecoalition/

Dasgupta, P. (2007). The Stern Review's economics of climate change. National Institute Economic Review, 199(1), 4-7.

Dasgupta, P. (2008). Discounting Climate Change. Journal of Risk and Uncertainty, 37, 141169.

Dennig, F., Budolfson, M.B., Fleurbaey, M., Siebert, A., \& Socolow, R.H. (2015). Inequality, climate impacts on the future poor, and carbon prices. PNAS, 112(52), 15827-15832. 
Diaz, D., \& Keller, K. (2016). A potential disintegration of the west antarctic ice sheet: Implications for economic analyses of climate policy. The American Economic Review, 106(5), 607-611.

Dietz, S., \& Stern, N. (2015). Endogenous Growth, Convexity of Damage and Climate Risk, How Nordhaus' Framework Supports Deep Cuts in Carbon Emissions. Econ J, 125, 574-620.

Dietz, S., Rising, J., Stoerk, T., \& Wagner, G. (2021). Economic impacts of tipping points in the climate system. Proceedings of the National Academy of Sciences, 118(34), e2103081118.

Drupp, M.A., Freeman, M.C., Groom, B., \& Nesje, F. (2018). Discounting

Disentangled. American Economic Journal Economic Policy, 10(4), 109-34.

Dumitru, O.A., Austermann, J., Polyak, V.J., et al. (2019). Constraints on global mean sea level during Pliocene warmth. Nature, 574, 233-236.

Energy Transitions Commission (2021). Making Clean Electrification Possible: 30 Years to Electrify the Global Economy.

Epstein, L.G., \& Zin, S. (1989). Substitution, Risk Aversion, and the Temporal Behavior of Consumption and Asset Returns: A Theoretical Framework. Econometrica, 57 (4), 937-969.

European Commission (2019). Eurobarometer Special 492 - Europeans' attitudes on EU energy policy.

Farmer, J.D., Hepburn, C., Mealy, P., \& Teytelboym, A. (2015). A Third Wave in the Economics of Climate Change. Environ Resource Econ, 62, 329-357.

Food and Land Use Coalition (2019). Growing Better: Ten Critical Transitions to Transform Food and Land Use. The Food and Land Use Coalition.

Food and Land Use Coalition (2021). About FOLU. https://www.foodandlandusecoalition.org/about/

Gilboa, I., \& Schmeidler, D. (1989). Maxmin expected utility with non-unique priors. Journal of Mathematical Economics, 18(2), 141-153.

Gillingham, K., Nordhaus, W., Anthoff, D., Blanford, G., Bosetti, V., Christensen, P., McJeon, H., \& Reilly, J. (2018). Modeling Uncertainty in Integrated Assessment of Climate Change: A Multimodel Comparison. Journal of the Association of Environmental and Resource Economists, 5(4), 791-826.

Gollier, C., \& Hammitt, J.K. (2014). The Long-Run Discount Rate Controversy. Annual Review of Resource Economics, 6(1), 273-295.

Grossman, S.J. (1981). The Informational Role of Warranties and Private Disclosure about Product Quality. The Journal of Law \& Economics, 24(3), 461-483.

Grossman, S.E., \& Stiglitz, J.E. (1980). On the Impossibility of Informationally Efficient Markets. American Economic Review, 70(3), 393-408.

Grubb, M., Wieners, C., \& Yang, P. (2021). Modeling myths: On DICE and dynamic realism in integrated assessment models of climate change mitigation. WIREs Clim Change. 12, e698. https://doi.org/10.1002/wcc.698

Grubler, A., Wilson, C., Bento, N., Boza-Kiss, B., Krey, V., McCollum, D.L., Rao, N.D., Riahi, K., Rogelj, J., De Stercke, S., Cullen, J., Frank, S., Fricko, O., Guo, F., Gidden, M., Havlík, P., 
Huppmann, D., Kiesewetter, G., Rafaj, P., Schoepp, W., \& Valin, H. (2018). A low energy demand scenario for meeting the $1.5^{\circ} \mathrm{C}$ target and sustainable development goals without negative emission technologies. Nat Energy, 3, 515-527.

Hänsel, M.C., Drupp, M.A., Johansson, D.J., Nesje, F., Azar, C., Freeman, M.C., Groom, B., \& Sterner, T. (2020). Climate economics support for the UN climate targets. Nature Climate Change, 10(8), 781-789.

Heal, G., \& Millner, A. (2018). Uncertainty and ambiguity in environmental economics: Conceptual issues. In P. Dasgupta, S. K. Pattanayak, \& V. K. Smith (Eds.), Handbook of Environmental Economics (Vol. 4, pp. 439-468). Elsevier.

Hsiang, S., Kopp, R., Jina, A., Rising, J., Delgado, M., Mohan, S., Rasmussen, D.J., Muir-Wood, R., Wilson, P., Oppenheimer, M., Larsen, K., \& Houser, T. (2017). Estimating economic damage from climate change in the United States. Science, 356(6345), 1362-1369.

Hurd, M.D., \& Smith, J.P. (2002). Expected Bequests and Their Distribution. RAND, Labor and Population Program Working Paper Series 03-10.

International Energy Agency (2021). Net Zero by 2050: A Roadmap for the Global Energy Sector.

International Monetary Fund (2021). G-20 Background Note: Reaching Net Zero Emissions.

IPCC (2014). Climate Change 2014: Synthesis Report. Contribution of Working Groups I, II and III to the Fifth Assessment Report of the Intergovernmental Panel on Climate Change [Core Writing Team, R.K. Pachauri and L.A. Meyer (eds.)]. IPCC, Geneva, Switzerland, 151 pp.

IPCC (2018). Global Warming of $1.5^{\circ} \mathrm{C}$. An IPCC Special Report on the impacts of global warming of $1.5^{\circ} \mathrm{C}$ above pre-industrial levels and related global greenhouse gas emission pathways, in the context of strengthening the global response to the threat of climate change, sustainable development, and efforts to eradicate poverty [Masson-Delmotte, $\mathrm{V}$., Zhai, P., Pörtner, H. -O., Roberts, D., Skea, J., Shukla, P.R., Pirani, A., Moufouma-Okia, W., Péan, C., Pidcock, R., Connors, S., Matthews, J.B.R., Chen, Y., Zhou, X., Gomis, M.I., Lonnoy, E., Maycock, T., Tignor, M., \& Waterfield, T. (eds ).]. In Press.

IPCC (2021). Climate Change 2021: The Physical Science Basis. Contribution of Working Group I to the Sixth Assessment Report of the Intergovernmental Panel on Climate Change [Masson-Delmotte, V., P. Zhai, A. Pirani, S. L. Connors, C. Péan, S. Berger, N. Caud, Y. Chen, L. Goldfarb, M. I. Gomis, M. Huang, K. Leitzell, E. Lonnoy, J. B. R. Matthews, T. K. Maycock, T. Waterfield, O. Yelekçi, R. Yu and B. Zhou (eds.)]. Cambridge University Press. In Press.

Kang, S., \& Eltahir, E.A.B. (2018). North China Plain threatened by deadly heatwaves due to climate change and irrigation. Nat. Commun., 9, 2894. https://doi.org/10.1038/s41467-01805252-y

Kaufman, N., Barron A.R., Krawczyk, W., Marsters, P., \& McJeon, H. (2020). A near-term to net zero alternative to the social cost of carbon for setting carbon prices. Nature Climate Change, 10, 1010-1014.

Keller, K., Bolker, B., \& Bradford, D. (2004). Uncertain climate thresholds and optimal economic growth. Journal of Environmental Economics and Management, 48(1), 723-741.

Kirman, A.P. (1992). Whom or What Does the Representative Individual Represent? Journal of Economic Perspectives, 6, 117-136. 
Kreps, D.M. (1979). A Representation Theorem for 'Preference for Flexibility'. Econometrica, 47(3), 565-577.

Kreps, D.M., \& Porteus, E.L. (1978). Temporal Resolution of Uncertainty and Dynamic Choice Theory. Econometrica, 46(1), 185-200. https://doi.org/10.2307/1913656.

Lemoine, D., \& Traeger, C.P. (2014). Watch Your Step: Optimal Policy in A Tipping Climate. American Economic Journal: Economic Policy, 6(1), 137-66.

Lemoine, D., \& Traeger, C.P. (2016). Economics of tipping the climate dominoes. Nature Climate Change, 6(5), 514.

Lenton, T.M., Held, H., Kriegler, E., Hall, J.W., Lucht, W., Rahmstorf, S., \& Schellnhuber, H.J. (2008). Tipping elements in the Earth's climate system. Proceedings of the National Academy of Sciences, 105(6), 1786-1793.

Lenton, T.M., Rockström, J., Gaffney, O., Rahmstorf, S., Richardson, K., Steffen, W., \& Schellnhuber, H.J. (2019). Climate tipping points - too risky to bet against. Nature, 575(7784), 592-595.

Lipsey, R., \& Lancaster, K. (1956). The General Theory of Second Best. The Review of Economic Studies, 24(1), 11-32.

Lontzek, T.S., Cai, Y., Judd, K.L., \& Lenton, T.M. (2015). Stochastic Integrated Assessment of Climate Tipping Points Indicates the Need for Strict Climate Policy. Nature Climate Change, $5,3-6$.

Maskin, E. (1979). Decision-Making Under Ignorance with Implications for Social Choice. Theory and Decision, 11, 319-337.

Meade, J.E. (1952). External economies and diseconomies in a competitive situation. Economic Journal, 62, 54-67.

Milly, P.C.D., Betancourt, J., Falkenmark, M., Hirsch, R.M., Kundzewicz, Z.W., Lettenmaier, D.P., \& Stouffer, R.J. (2008). Stationarity Is Dead, Whither Water Management?. Science, 319, 573-574.

Moore, F.C., \& Diaz, D.B. (2015). Temperature impacts on economic growth warrant stringent mitigation policy. Nature Climate Change, 5(2), 127.

Moyer, E., Woolley, M., Matteson, N., Glotter, M., \& Weisbach, D. (2014). Climate Impacts on Economic Growth as Drivers of Uncertainty in the Social Cost of Carbon. The Journal of Legal Studies, 43(2), 401-425.

Neelin, J.D., Bracco, A., Luo, H., McWilliams, J.C., \& Meyerson, J.E. (2010). Considerations for parameter optimization and sensitivity in climate models. Proceedings of the National Academy of Sciences, 107(50), 21349-21354.

Nordhaus, W.D. (1991). To slow or not to slow: The economics of the greenhouse. Economic Journal, 101, 920-937.

Nordhaus, William. (2007). A Review of the Stern Review on the Economics of Climate Change. Journal of Economic Literature, 45, 686-702.

Nordhaus, W.D. (2009). An Analysis of the Dismal Theorem. Cowles Foundation Discussion Paper No. 1686. 
Nordhaus, W.D. (2018a). Climate Change: The Ultimate Challenge for Economics. Nobel Lecture in Economic Sciences.

Nordhaus, W.D. (2018b). Projections and Uncertainties about Climate Change in an Era of Minimal Climate Policies. American Economic Journal: Economic Policy, 10(3), 333-360.

Pindyck, R.S. (2013). Climate Change Policy: What Do the Models Tell Us? Journal of Economic Literature, 51(3), 860-872.

Ramsey, F.P. (1928). A Mathematical Theory of Saving. Economic Journal, 38(4), 543-559.

Rawls, J. (1971). A Theory of Justice. Belknap Press of Harvard University Press.

Ripple, W.J., Wolf, C., Newsome, T.M., Barnard, P., \& Moomaw, W.R. (2020). World

Scientists' Warning of a Climate Emergency. BioScience, 70(1), 8-12.

Rodrik, D. (2015). Economics Rules: The Rights and Wrongs of The Dismal Science, pp. 213. New York: W.W. Norton.

Sandmo, A (1975). Optimal Taxation in the Presence of Externalities. Swedish Journal of Economics, 77, 86-98.

Sen, A. (2009). The Idea of Justice. London: Allen Lane.

Schumacher, I. (2018). The Aggregation Dilemma in Climate Change Policy Evaluation. Climate Change Economics, 09, 03.

Shiller, R. (1981). Do Stock Prices Move Too Much to be Justified by Subsequent Changes in Dividends? American Economic Review, 71(3), 421-36.

Stern, N. (1977). Welfare Weights and the Elasticity of the Marginal Valuation of Income. In M. J. Artis and A. R. Nobay, eds., Studies in Modern Economic Analysis: The Proceedings of the Association of University Teachers of Economics, Edinburgh, 1976. Oxford: Basil Blackwell.

Stern, N. (2007). The Economics of Climate Change: The Stern Review. Cambridge University Press.

Stern, N. (2008). The Economics of Climate Change. American Economic Review, 98(2), 137.

Stern, N. (2014a). Ethics, Equity and the Economics of Climate Change Paper 1: Science and Philosophy. Economics and Philosophy, 30(3), 397-444.

Stern, N. (2014b). Ethics, Equity and the Economics of Climate Change Paper 2: Economics and Politics. Economics and Philosophy, 30(3), 445-501.

Stern, N. (2015). Why Are We Waiting? The Logic, Urgency and Promise of Tackling Climate Change. MIT Press.

Stern, N. \& Stiglitz, J. (2021). The Social Cost of Carbon, Risk, Distribution, Market Failures: An alternative approach. NBER Working Paper 28472.

Stern, N., \& Stiglitz, J.E., et al (2017). Report of the high-level commission on carbon prices. World Bank.

Stiglitz, J.E. (1975). Incentives, Risk and Information: Notes Towards a Theory of Hierarchy. Bell Journal of Economics, 6(2), 552-579. 
Stiglitz, J.E. (1982). The Rate of Discount for Cost-Benefit Analysis and the Theory of the Second Best. Discounting for Time and Risk in Energy Policy, Lind, R. (ed.), Resources for the Future, 151-204.

Stiglitz, J.E. (1994). Whither Socialism? MIT Press.

Stiglitz, J.E. (2002). Information and the Change in the Paradigm in Economics. Abbreviated version of Nobel lecture. American Economic Review, 92(3), 460-501.

Stiglitz, J.E. (2011). Rethinking Macroeconomics: What Failed, and How to Repair It. Journal of the European Economic Association, 9 (4), 591-645.

Stiglitz, J.E. (2018). Pareto efficient taxation and expenditures, Pre- and re-distribution. Journal of Public Economics, 162, 101-119.

Stiglitz, J.E. (2019). Addressing climate change through price and non-price interventions. European Economic Review, 119, 594-612.

Stiglitz, J.E., \& Greenwald, B. (2014). Creating a learning society, A new approach to growth, development, and social progress. Columbia University Press.

Stroebel, J. \& Wurgler, J.A. (2021). What do you think about climate finance? Available at SSRN: https://ssrn.com/abstract=3898013.

Systemiq (2021) The Paris Effect - COP26 Edition: How Tipping Points Can Accelerate and Deliver a Prosperous Net Zero Economy.

UNEP (2020). Emissions gap report. https://www.unep.org/emissions-gap-report-2020.

UNEP (2021). Emissions Gap Report 2021: The Heat Is On.

https://www.unep.org/resources/emissions-gap-report-2021.

United States Government - Interagency Working Group on Social Cost of Greenhouse Gases (2016). Technical Support Document: Technical Update of the Social Cost of Carbon for Regulatory Impact Analysis - Under Executive Order 12866.

https://www.epa.gov/sites/default/files/2016-12/documents/sc_co2_tsd_august_2016.pdf

Vohra, K., Vodonos, A., Schwartz, J., Marais, E.A., Sulprizio, M.P., \& Mickley, L.J., (2021). Global mortality from outdoor fine particle pollution generated by fossil fuel combustion: Results from GEOS-Chem. Environmental Research, 195,110754.

Wang, P., Deng, X., Zhou, H. \& Yu, S. (2019). Estimates of the social cost of carbon: A review based on meta-analysis, Journal of Cleaner Production, 209, 1494-1507.

Weitzman, M.L. (1974). Prices vs. Quantities. Review of Economic Studies, 41, 477-91.

Weitzman, M.L. (2007). A Review of The Stern Review on the Economics of Climate Change. Journal of Economic Literature, XLV, 703-724.

Weitzman, M.L. (2009). On modeling and interpreting the economics of catastrophic climate change. Review of Economics and Statistics, 91(1), 1-19.

Weitzman, M.L. (2011). Fat-Tailed Uncertainty in the Economics of Catastrophic Climate Change. Review of Environmental Economics and Policy, 5(2), 275-92.

Weitzman, M. L. (2012). GHG Targets as Insurance against Catastrophic Climate Damages. Journal of Public Economic Theory, 14, 221-244. 
Wilhelm, M.O. (1996). Bequest Behavior and the Effect of Heirs' Earnings, Testing the Altruistic Model of Bequests. The American Economic Review, 86(4), 874-892.

Wolff, E.N., \& Gittleman, M. (2014). Inheritances and the distribution of wealth or whatever happened to the great inheritance boom?. J Econ Inequal, 12, 439-468.

Xu, C., Kohler, T.A., Lenton, T.M., Svenning, J.-C., \& Scheffer, M. (2020). Future of the human climate niche. Proceedings of the National Academy of Sciences, 117(21), 11350-11355.

Yumashev, D., Hope, C., Schaefer, K., Riemann-Campe, K., Iglesias-Suarez, F., Jafarov, E., Burke, E.J., Young, P.J., Elshorbany, Y., \& Whiteman, G. (2019). Climate policy implications of nonlinear decline of arctic land permafrost and other cryosphere elements. Nature Communications, 10, 1900. 